\title{
CD4+ T cell expression of the IL-10 receptor is necessary for facial motoneuron survival after axotomy
}

Elizabeth M. Runge ${ }^{1,2^{*}}$, Abhirami K. Iyer ${ }^{3}$, Deborah O. Setter ${ }^{1,2}$, Felicia M. Kennedy ${ }^{1,2}$, Virginia M. Sanders ${ }^{4}$ and Kathryn J. Jones ${ }^{1,2}$

\begin{abstract}
Background: After peripheral nerve transection, facial motoneuron (FMN) survival depends on an intact CD4+ T cell population and a central source of interleukin-10 (IL-10). However, it has not been determined previously whether CD4+ T cells participate in the central neuroprotective IL-10 cascade after facial nerve axotomy (FNA).

Methods: Immunohistochemical labeling of CD4+ T cells, pontine vasculature, and central microglia was used to determine whether CD4+ T cells cross the blood-brain barrier and enter the facial motor nucleus (FMNuc) after FNA. The importance of IL-10 signaling in CD4+ T cells was assessed by performing adoptive transfer of IL-10 receptor beta (IL10RB)-deficient CD4+ T cells into immunodeficient mice prior to injury. Histology and GPCR were utilized to determine the impact of IL-10RB-deficient T cells on FMN survival and central gene expression after FNA. Flow cytometry was used to determine whether IL-10 signaling in T cells was necessary for their differentiation into neuroprotective subsets.

Results: CD4+ T cells were capable of crossing the blood-brain barrier and associating with reactive microglial nodules in the axotomized FMNuc. Full induction of central IL-10R gene expression after FNA was dependent on CD4+ T cells, regardless of their own IL-10R signaling capability. Surprisingly, CD4+ T cells lacking IL-10RB were incapable of mediating neuroprotection after axotomy and promoted increased central expression of genes associated with microglial activation, antigen presentation, $T$ cell co-stimulation, and complement deposition. There was reduced differentiation of IL-10RB-deficient CD4+ T cells into regulatory CD4+ T cells in vitro.

Conclusions: These findings support the interdependence of IL-10- and CD4+ T cell-mediated mechanisms of neuroprotection after axotomy. CD4+ T cells may potentiate central responsiveness to IL-10, while IL-10 signaling within CD4+ T cells is necessary for their ability to rescue axotomized motoneuron survival. We propose that loss of IL-10 signaling in CD4+ T cells promotes non-neuroprotective autoimmunity after FNA.
\end{abstract}

Keywords: Autoimmune, Axotomy, IL-10, Motoneuron, Nerve injury, Neuroprotection, T cell

\footnotetext{
* Correspondence: erunge@iu.edu

${ }^{1}$ Department of Anatomy, Cell Biology, and Physiology, Indiana University

School of Medicine, 635 Barnhill Drive, Medical Science Building 5035,

Indianapolis, IN 46202, USA

${ }^{2}$ Research and Development, Richard L. Roudebush VA Medical Center, Indianapolis, IN, USA

Full list of author information is available at the end of the article
}

(c) The Author(s). 2020 Open Access This article is licensed under a Creative Commons Attribution 4.0 International License, which permits use, sharing, adaptation, distribution and reproduction in any medium or format, as long as you give appropriate credit to the original author(s) and the source, provide a link to the Creative Commons licence, and indicate if changes were made. The images or other third party material in this article are included in the article's Creative Commons licence, unless indicated otherwise in a credit line to the material. If material is not included in the article's Creative Commons licence and your intended use is not permitted by statutory regulation or exceeds the permitted use, you will need to obtain permission directly from the copyright holder. To view a copy of this licence, visit http://creativecommons.org/licenses/by/4.0/. The Creative Commons Public Domain Dedication waiver (http://creativecommons.org/publicdomain/zero/1.0/) applies to the data made available in this article, unless otherwise stated in a credit line to the data. 


\section{Background}

Maintenance of central motoneuron survival is paramount in order for functional recovery to be achieved following peripheral nerve transection and disconnection from target musculature. After facial nerve axotomy (FNA), immunodeficient mice lacking $\mathrm{B}$ and $\mathrm{T}$ cells exhibit more facial motoneuron (FMN) death in the facial motor nucleus (FMNuc) compared to wild-type (WT) mice with intact immune systems $[1,2]$. In the FNA model of peripheral nerve injury, the neuroprotective capacity of the adaptive immune system is specific to Th2 CD4+ T cells, which are sufficient for rescuing FMN survival when adoptively transferred into immunodeficient RAG- $2^{-/-}$mice $[3,4]$. The precise mechanism of CD4+ T cell-mediated neuroprotection is unknown, but recent research shows that the peripheral immune system plays a major role in modulating the central glial response to facial nerve injury [5].

Naive CD4+ T cells must encounter major histocompatibility complex (MHC) class II on antigen presenting cells (APCs) in the periphery and become activated in an antigen-specific fashion in order to become neuroprotective [6]. After peripheral activation and clonal expansion, $\mathrm{T}$ cells are next attracted to the FMNuc by centrally derived chemokines [7-9]. It has been inferred from immunohistochemical (IHC) studies demonstrating the presence of CD3+ $\mathrm{T}$ lymphocytes in axotomized FMNuc that these cells cross the blood-brain barrier (BBB) [10-12]. However, further evidence utilizing histological labeling of the FMNuc vasculature is needed to strengthen the hypothesis that $\mathrm{T}$ cells (and the CD4+ T subset in particular) exist in CNS parenchyma after axotomy and are not confined to penetrating blood vessels, which are difficult to visualize without appropriate labeling techniques. After homing to the injured FMNuc, T cells must again encounter MHC class II on microglia in order to confer neuroprotection [6]. Microglia proliferate in the FMNuc after axotomy [13], phagocytize dead neurons [14], and express MHC class I and II molecules, on which they may present neuronal antigen to infiltrating $\mathrm{T}$ cells $[15,16]$.

The anti-inflammatory cytokine interleukin-10 (IL-10) has received considerable attention in neuroinflammation research due to its modulatory effects on glial reactivity and pro-survival influences on neurons $[17,18]$. IL-10 is an important mediator of the neuroprotective capability of CD4+ T cells after FNA; in the absence of IL-10, axotomy induces greater FMN death that is resistant to rescue by CD4+ T cells. Yet, despite the necessity of both IL-10 and CD4+ T cells for neuroprotection after FNA, CD4+ T cells are not a requisite source of IL-10. IL-10 likely derives from CNS resident cells in the FMNuc, rather than CD4+ T cells. Although absence of CD4+ T cells results in slightly decreased IL-10 levels in the FMNuc at an early time point after axotomy, this modest difference is unlikely to wholly explain the survival deficit observed in RAG- $2^{-1-}$ mice at
1 month post-operation [19]. It has not been elucidated previously whether the dual actions of IL-10- and CD4+ T cell-mediated neuroprotection after FNA are interrelated or independent of one another. This information is necessary to understand the process of endogenous immunemediated neuroprotection and thereby identify potential mechanisms that can be exploited for the treatment of nerve injury and motoneuron disease.

For the first part of this study, it was hypothesized that CD4+ $\mathrm{T}$ cells play an integral role in the central IL-10 cascade after FNA by regulating IL-10 receptor (IL-10R) expression in the FMNuc. The ability of peripheral CD4+ $\mathrm{T}$ cells to regulate central gene expression in the axotomized FMNuc has been previously established [5]. Prior to testing this hypothesis, it was necessary to determine whether $\mathrm{T}$ cells must communicate with cells in the FMNuc remotely (i.e., across the BBB) or are capable of traveling into the FMNuc parenchyma and interacting directly with resident cells there. This information would indicate whether central expression of IL-10R and other markers are potentially effected by direct $\mathrm{T}$ cell contact.

The second part of this study was performed to investigate IL-10R expression by infiltrating $\mathrm{T}$ cells themselves. IL-10 directly induces $\mathrm{T}$ cell tolerance to specific antigen [20]. Furthermore, it has been shown that tolerized $\mathrm{T}$ cells can inhibit further antigen presentation events and suppress the proliferation of other $\mathrm{T}$ cells in an antigenspecific fashion [21, 22]. Conversely, effector T cells (particularly Th1 and Th17 cells) can activate APCs (including microglia) to a pro-inflammatory state [23-26]. Therefore, an IL-10 cascade in the axotomized FMNuc could reflect a mechanism regulating autoimmune responses to neuronal self-antigen released after FNA. We propose that IL-10R expression on CD4+ T cells is necessary for their ability to confer neuroprotection, potentially by influencing $\mathrm{T}$ cell activation against self-antigen and subsequent modulation of the glial microenvironment by $\mathrm{T}$ cells after axotomy.

\section{Methods}

Animals: all mice were obtained from The Jackson Laboratory. Strains utilized include C57BL/6 J (WT), B6(Cg)$\operatorname{Rag}^{\text {tm1.1Cgn }} / \mathrm{J}$ (RAG-2 ${ }^{-/-}$), and B6.129S2-Il10rb ${ }^{\text {tm1Agt }} / \mathrm{J}$ $\left(I l 10 \mathrm{rb}^{-1-}\right)$. Only female mice were used due to the tendency of males to engage in fighting behavior after axotomy, leading to infections at the surgery site that complicate immune profiles. Animals were obtained at 7 weeks of age and allowed to acclimate for at least 1 week prior to use. Mice were housed in sterilized microisolator cages equipped with a laminar flow system to maintain a pathogen-free environment and allowed access to autoclaved food pellets and water ad libitum.

Adoptive transfer: donor animals were utilized at a 1:1 ratio to recipients. Following $\mathrm{CO}_{2}$ euthanasia and cervical dislocation, spleens were removed and mechanically 
dissociated using the plunger of a sterile syringe. Dissociated splenocytes were incubated with $\mathrm{CD} 4$ magnetic beads (Miltenyi Biotec, 130-117-043) and manually sorted using LS columns (Miltenyi Biotec, 130-042-401) following manufacturer instructions. The eluent was then passed through a new column a second time to enhance cell purity. Flow cytometry revealed sorted $\mathrm{CD} 4+\mathrm{T}$ cell purity to be $96 \%$ (data available upon request). Host mice received 5 million sorted CD4+ T cells per $100 \mu \mathrm{l}$ PBS injection via tail vein 1 week prior to FNA to allow for engraftment of transferred cells.

Surgical procedure: FNA was performed when mice were 8 weeks old. The detailed surgical procedure has been published previously [27]. Briefly, animals were anesthetized with $2.5 \%$ isoflurane, and a small $(\sim 4 \mathrm{~mm})$ incision was made posterior to the right ear protuberance using aseptic techniques. The underlying fascia was dissected bluntly to expose the facial nerve, which was severed just distal to its emergence from the stylomastoid foramen. The nerve stumps were either pushed away, or a small segment of the distal nerve stump was resected to prevent reconnection. The left facial nerve was left intact as an internal control. Following surgery, successful transection of the facial nerve was confirmed by behavioral assessment of eye blink and whisking reflexes.

Immunohistochemistry: The 14 days post-operation (dpo) time point was selected for analysis as this represents the peak of $\mathrm{T}$ cell infiltration in the literature [11, 16]. Animals $(n=3)$ were euthanized via ketaminexylazine overdose and exsanguination followed by perfusion with $2 \%$ buffered paraformaldehyde (PFA). Brains were removed, post-fixed in $2 \%$ PFA for $1-3 \mathrm{~h}$, and equilibrated in $30 \%$ sucrose prior to embedding in OCT medium. Eight micrometer brainstem sections containing the FMNuc were collected and blocked for $1 \mathrm{~h}$ at room temperature in $10 \%$ donkey serum, $1 \%$ bovine serum albumin, and $0.01 \%$ Triton X-100 in PBS, followed by incubation in primary antibody (Table 1) for

Table 1 Antibodies utilized for $\mathrm{IHC}$

\begin{tabular}{llll}
\hline & Antibody & $\begin{array}{l}\text { Manufacturer } \\
\text { and Cat. no. }\end{array}$ & Dilution \\
\hline Primary & Rabbit anti-IBA1 & $\begin{array}{l}\text { Thermo Fisher } \\
\text { 019-19741 }\end{array}$ & $1: 500$ \\
& Rat anti-CD4 488 & $\begin{array}{l}\text { BioLegend } \\
100423\end{array}$ & $1: 100$ \\
& Rabbit anti-CD3 & Abcam ab16669 & $1: 200$ \\
& Rabbit anti-CD31 & $\begin{array}{l}\text { Abcam } \\
\text { ab124432 }\end{array}$ & $1: 500$ \\
Secondary & $\begin{array}{l}\text { Donkey anti-rabbit 568 } \\
\text { (used for IBA1, CD3, CD31) }\end{array}$ & Abcam ab175470 & $1: 1000$ \\
& $\begin{array}{l}\text { Donkey anti-rat 488 (used } \\
\text { for CD4) }\end{array}$ & $\begin{array}{l}\text { Thermo Fisher } \\
\text { A21208 }\end{array}$ & $1: 1000$ \\
\hline
\end{tabular}

$4 \mathrm{~h}$ at room temperature or $16 \mathrm{~h}$ at $4{ }^{\circ} \mathrm{C}$. Sections were washed $3 \times 5 \mathrm{~min}$ in PBS prior to incubation with secondary antibody for $1 \mathrm{~h}$ at room temperature. When fluorescent Nissl staining was desired, NeuroTrace ${ }^{\text {tw }} 435$ / 455 Blue Fluorescent Nissl Stain (Thermo Fisher, N21479) was diluted 1:100 in PBS, applied to sections for $20 \mathrm{~min}$ after removing secondary antibody, and washed $3 \times 5 \mathrm{~min}$ in PBS prior to mounting in ProLong Gold Antifade medium (Invitrogen, P36930). Images were captured with an Olympus BX50 inverted fluorescent microscope using the Olympus cellSens Entry 1.9 software, and level adjustments to reduce background were performed uniformly across control and axotomized FMNuc in Adobe Photoshop.

Motoneuron counting: animals ( $n=4-5$ /group) were euthanized at 28 dpo using $\mathrm{CO}_{2}$ inhalation and cervical dislocation. Brains were removed and flash-frozen at the interface of a pre-chilled 37.5\% 2-methylbutane/62.5\% 1bromobutane biphasic solution prior to cryosectioning. Brainstem sections spanning the caudal-rostral extent of the FMNuc were collected at $25 \mu \mathrm{m}$, fixed for $15 \mathrm{~min}$ in $4 \%$ PFA, and stained with $0.04 \%$ thionin acetate solution followed by ethanol dehydration series. Sections were cleared in CitriSolv overnight or up to 3 days and subsequently coverslipped using Permount toluene-based mounting medium. For counting, an impartial investigator coded all slides. A separate blinded investigator used a Leica DMRB light microscope and Neurolucida software (version 10.31) to manually count motoneurons in the FMNuc. To avoid double counting, only FMN profiles with a nucleus and nucleolus were counted. Mean percentage FMN survival was quantified by dividing the total number of FMN on the axotomized side by the total number on the control side and multiplying by $100 \%$. One-way analysis of variance (ANOVA) followed by a Student-Newman-Keuls post-hoc test was performed with an alpha of 0.05 .

Laser capture microdissection, RNA extraction, reverse transcription (RT), and qPCR: $N=4-11$ mice/group were analyzed at the 14 dpo time point according to the rationale described in previous experiments; additionally, this time point represents the peak of microglial gene expression in the FMNuc after axotomy [5]. All procedures were performed as described in Setter et al. [5]. Briefly, brains were removed, flash-frozen, and sectioned onto PEN membrane slides (Leica Microsystems, 11505158). Slides were stained with thionin, and a Leica ASLMD microscope was used to collect the right and left FMNuc. RNA extraction and RT were performed using an Arcturus PicoPure ${ }^{\circ}$ RNA Isolation Kit (Applied Biosystems, KIT0204) and SuperScript ${ }^{\odot}$ VILO Master Mix (Invitrogen, 11755050), respectively. TaqMan ${ }^{\circ}$ FAM gene expression assays were used to perform qPCR (Table 2). CT values were normalized to the reference 
Table 2 TaqMan ${ }^{\oplus}$ assays utilized in this study

\begin{tabular}{lll}
\hline Gene & TaqMan ID & RefSeq accession number \\
\hline B2m & Mm00437762_m1 & NM_009735.3 \\
C3 & Mm01232779_m1 & $\begin{array}{l}\text { (GenBank-no RefSeq numbers } \\
\text { available) BC029976.1, BC043338.1, } \\
\text { DQ408205.1, EU868829.1, } \\
\end{array}$ \\
& & HM856604.1, K02782.1 \\
Cd40 & Mm00441891_m1 & NM_011611.2, NM_170702.2, \\
& & NM_170703.2, NM_170704.2, \\
Cd86 & Mm00444543_m1 & NR_027852.1 \\
Gapdh & Mm9919388.3 \\
H2ab1 & Mm00439216_m1 & NM_001289726.1, NM_008084.3 \\
Nos2 & Mm00440502_m1 & NM_010927.3 \\
Tnf & Mm00443260_g1 & NM_013693.3 \\
\hline
\end{tabular}

gene Gapdh and fold changes in mRNA expression between axotomized and control FMNuc were calculated. Because $\operatorname{Tnf}$ is only expressed on the axotomized FMNuc, the $\Delta \Delta C T$ value was calculated using a spleen cDNA standard, and its levels in axotomized FMNuc are expressed relative to WT spleen. The same spleen standard was used for comparison across all samples. Outliers were detected using the Grubbs' test (GraphPad QuickCalcs). One-way ANOVA followed by Student-Newman-Keuls multiple comparisons was performed with an alpha of 0.05 to determine significance.

Cell culture: anti-CD3e (BD Biosciences, 553057) at $10 \mu \mathrm{g} / \mathrm{mL}$ concentration in sterile PBS was incubated on 6well flat-bottom tissue culture plates overnight at $4{ }^{\circ} \mathrm{C}$. Spleens ( $n=3$ /group) were dissociated in sterile FACS buffer, subjected to RBC lysis, and resuspended in RPMI 1640 supplemented with $10 \%$ heat inactivated FBS, $2 \mathrm{mM} \mathrm{L-glu-}$ tamine, $50 \mu \mathrm{M} \beta$-mercaptoethanol, and $1 \%$ penicillin/ streptomycin. 4-6 $610^{6}$ cells were deposited per well on pre-incubated and washed plates (stimulated cells) or PBS- only plates (unstimulated cells). Two micrograms per milliliter of anti-CD28 (BD Biosciences, 553294) was added to the stimulated cells, and plates were incubated overnight at $37^{\circ} \mathrm{C}$. The next day, cells were stimulated further with 10 $\mathrm{ng} / \mathrm{ml}$ PMA and $1000 \mathrm{ng} / \mathrm{ml}$ ionomycin for $4-6 \mathrm{~h}$. Brefeldin A was added at $10 \mu \mathrm{g} / \mathrm{ml}$ for the last $3 \mathrm{~h}$ to all wells (both stimulated and unstimulated).

Flow cytometry: cells were harvested and blocked with anti-CD16/CD32 at 1:1000 in FACS buffer for $15 \mathrm{~min}$ before washing and staining for surface markers TCR $\beta$ and CD4 for 30 min on ice. Cells were washed, fixed in 1\% PFA for $15 \mathrm{~min}$, and washed again prior to permeabilization in FACS buffer $+0.1 \%$ saponin for $15 \mathrm{~min}$ at room temperature. Antibody cocktails for intracellular staining were mixed in FACS buffer $+0.1 \%$ saponin and applied to cells for $30 \mathrm{~min}$ at room temperature. Antibody information can be found in Table 3. Cells were washed, resuspended in FACS buffer, and stored at $4{ }^{\circ} \mathrm{C}$ until flow cytometry was performed (within 1 day). Data was acquired using a Fortessa X20 flow cytometer. A minimum number of 10,000 events were collected using the BD FACSDiva software. FCS files were analyzed using Flowjo 10. Cells were first gated for singlets, and CD4+ T cells and downstream T cell helper subset populations were defined following the representative gating strategies depicted in Fig. 1. Comparison of cell populations was performed in GraphPad Prism using one-way ANOVA followed by Student-Newman-Keuls multiple comparisons with an alpha of 0.05 to determine significance.

\section{Results}

It is unknown whether the CD4+ $\mathrm{T}$ cells responsible for mediating neuroprotection after axotomy are capable of infiltrating into the CNS parenchyma, or alternatively whether they must communicate with CNS resident cells across the BBB. Previous work using single-label IHC has reported the presence of $\mathrm{CD} 3+, \mathrm{CD} 4+$, and $\mathrm{CD} 8+$

Table 3 Antibodies utilized for flow cytometry

\begin{tabular}{|c|c|c|}
\hline Antibody & Manufacturer and cat. no. & Dilution \\
\hline APC anti-mouse TCR $\beta$ chain & BioLegend 109212 & $1: 50$ \\
\hline Alexa Fluor 488 anti-mouse CD4 & BioLegend 100423 & 1:800 \\
\hline BV 421 anti-mouse CD4 & BioLegend 100437 & $1: 50$ \\
\hline BV 711 anti-mouse IL-4 & BioLegend 504133 & $1: 50$ \\
\hline BV 421 anti-mouse IFN- $\gamma$ & BioLegend 505829 & $1: 50$ \\
\hline BV 711 anti-mouse IL-17A & BioLegend 506941 & $1: 50$ \\
\hline BV 711 anti-mouse CD25 & BioLegend 102049 & $1: 50$ \\
\hline PE anti-GATA3 & BioLegend 653803 & $1: 50$ \\
\hline PE/Dazzle ${ }^{\text {TM }} 594$ anti-T-bet & BioLegend 644827 & $1: 50$ \\
\hline PE anti-RORyt & Invitrogen AFKJS-9 & $1: 50$ \\
\hline Alexa Fluor 488 anti-mouse/rat/human FOXP3 & BioLegend 320011 & 1:100 \\
\hline Purified anti-mouse CD16/32 & BioLegend 101310 & 1:1000 \\
\hline
\end{tabular}




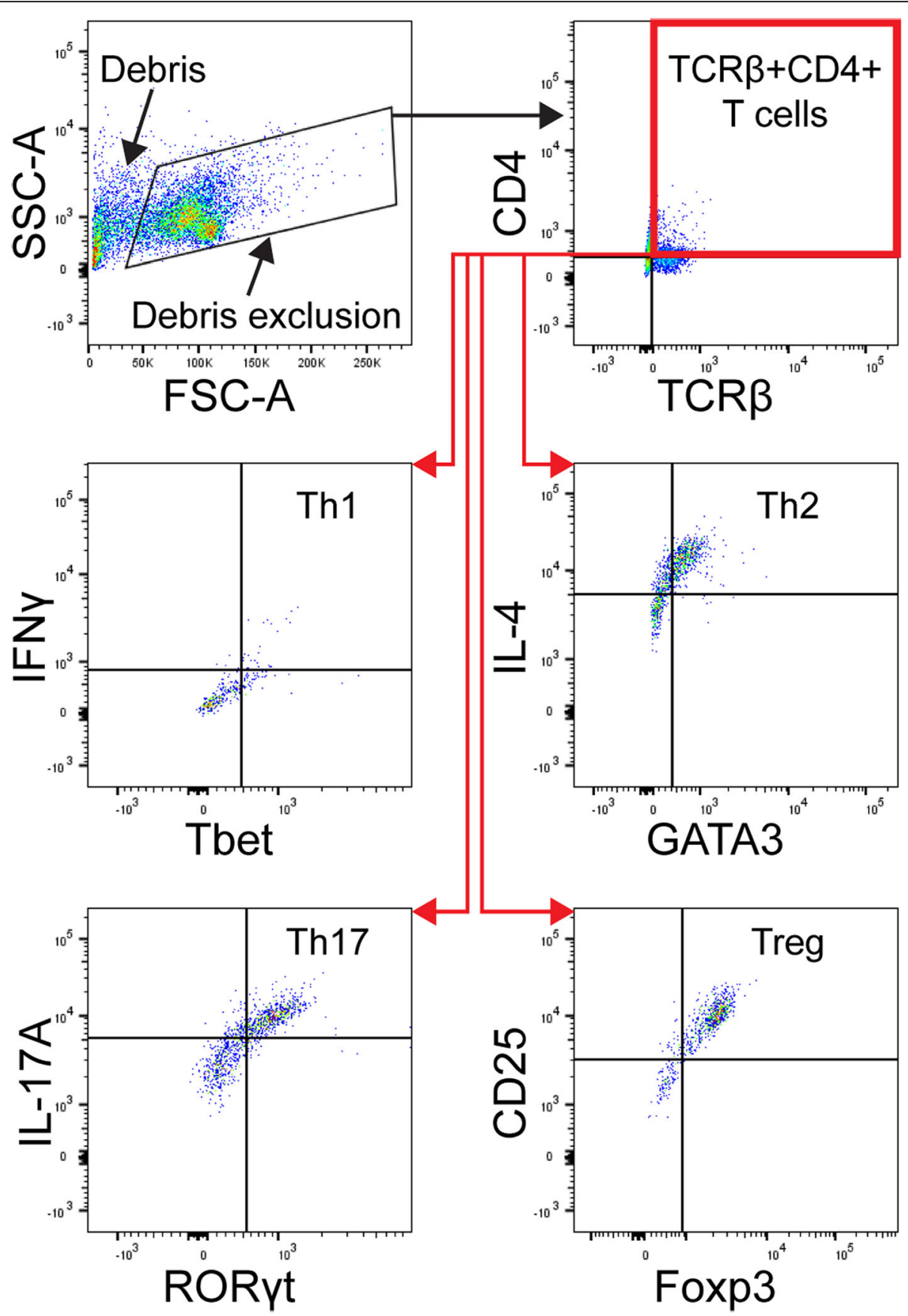

Fig. 1 Diagram depicting representative gating strategies for delineating CD4+ T cell subset populations. Following gating for singlets and debris exclusion, the CD4+ T cell population was selected based on CD4 and TCR $\beta$ expression. Within this population, the Th1 subset was defined as TBET $^{+}$IFNY ${ }^{+}$, Th2 as GATA3 ${ }^{+} I L-4^{+}$, Th17 as RORYt ${ }^{+} I L-17 A^{+}$, and regulatory T (Treg) helper subset as CD25 ${ }^{\text {high }} \mathrm{FOXP3}^{+}$

cells in the FMNuc after axotomy [11, 16, 28-30]. However, given the limitations of single-marker IHC as well as the potential expression of CD4 on non-T cells, including microglia and macrophages [31], it was necessary to perform co-IHC of CD3 with CD4 to demonstrate that true CD4+ T cells infiltrate the FMNuc after FNA where they may potentially interact with centrally located cells.
Antibodies specific for CD3 and CD4 antigen revealed no infiltrate in the unoperated FMNuc (Fig. 2a). In the contralateral axotomized FMNuc, infiltrates of CD3+ and CD4+ cells were detected (Fig. 2b-f). In every tissue section analyzed, all CD4+ cells observed infiltrating the FMNuc were $\mathrm{CD} 3+$, but not every $\mathrm{CD} 3+\mathrm{T}$ cell was $\mathrm{CD} 4+$, indicating that $\mathrm{CD} 8+\mathrm{T}$ cells may also infiltrate the FMNuc after 


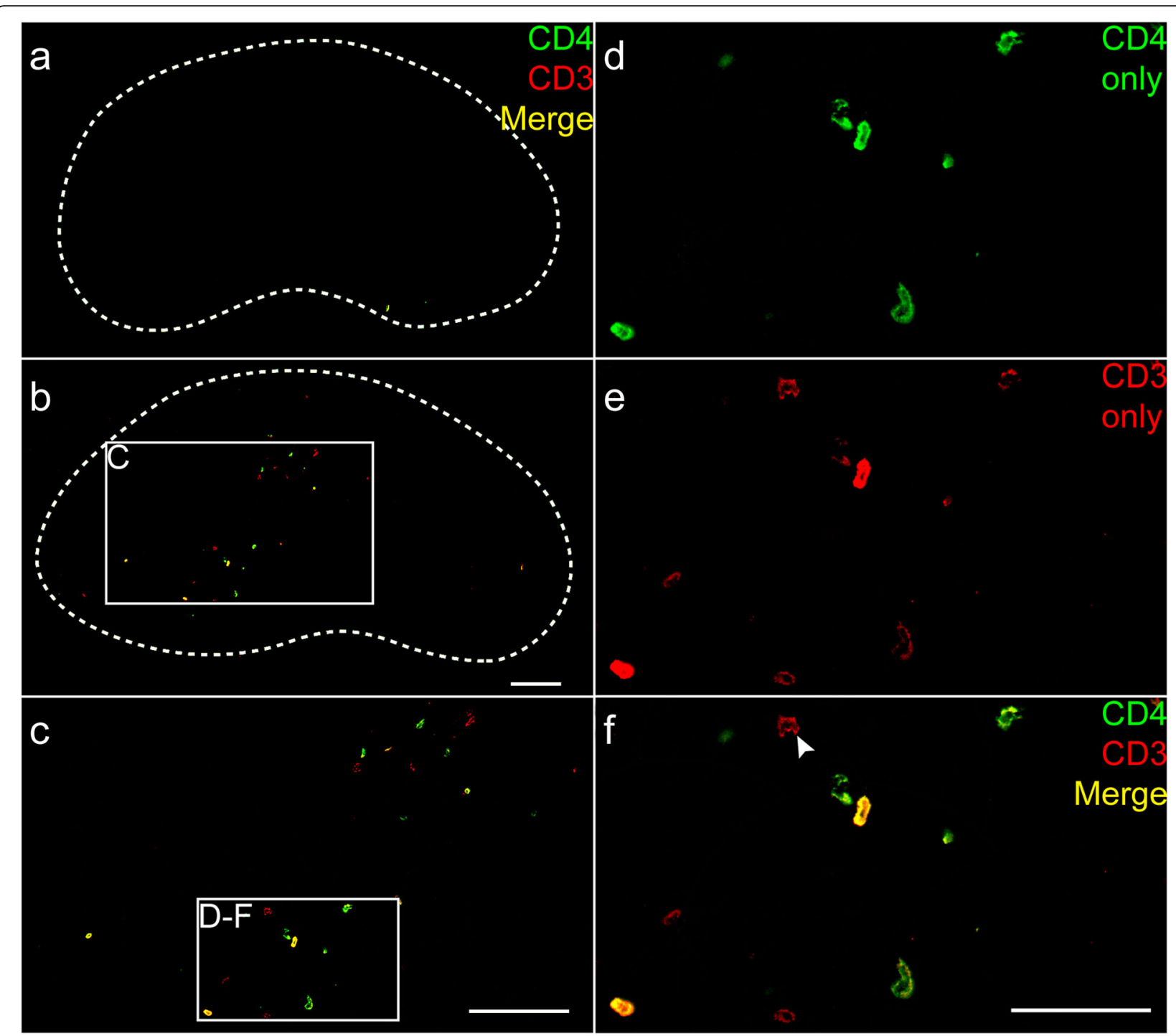

Fig. $2 \mathrm{HC}$ identification of CD3 + CD4+ T cells in the FMNuc. a Control FMNuc at $14 \mathrm{dpo}$. White dashed line indicates boundary of FMNuc. b Low power image of axotomized FMNuc at 14 dpo with T cell infiltration. c Higher power image of boxed area in $\mathbf{b}$. $\mathbf{d}$ High power image of boxed area in $\mathbf{c}$, CD4 channel only (green). e Same field as $\mathbf{d}$ showing CD3 channel only (red). f Overlaid channels in $\mathbf{d}$ and e showing CD3+/CD4- (white arrowhead) and CD3+/CD4+ T cells. Scale bar in $\mathbf{b}=100 \mu \mathrm{m}$ and applies to $\mathbf{a}$ and $\mathbf{b}$. Scale bar in $\mathbf{c}=100 \mu \mathrm{m}$. Scale bar in $\mathbf{d}=50 \mu \mathrm{m}$ and applies to $\mathbf{d}-\mathbf{f}$

axotomy (Fig. 2d-f). Although CD4+ T cells were detected in the FMNuc after axotomy, this observation alone was not sufficient to determine whether they are capable of interacting directly with cells in CNS parenchyma, or whether they are restricted to the vascular compartment. In combination with anti-CD4 to label $\mathrm{T}$ cells and a fluorescent Nissl stain to label neurons, an antibody against CD31 was used to visualize vasculature in the FMNuc. This triple stain revealed the presence of small penetrating blood vessels in the control FMNuc without evidence of $\mathrm{T}$ cell infiltration (Fig. 3a). CD4+ T cells were detectable in the axotomized FMNuc at $14 \mathrm{dpo}$. These $\mathrm{T}$ cells appeared not to be contained within CD31-labeled blood vessels, indicating that they are capable of extravasating into the CNS parenchyma (Fig. 3b-d). Furthermore, some $\mathrm{T}$ cells appeared to be in close proximity to injured motoneurons (Fig. 3c, d, arrowheads).

CD4+ T cells must interact with MHC class II on a central APC to mediate neuroprotection after axotomy [6]. With the ability of CD4+ T cells to extravasate into the FMNuc parenchyma established, potential associations of CD4+ T cells with microglia were next evaluated. Double labeling for CD4 and IBA1 in the unaxotomized FMNuc was negative for reactive microglia or infiltrating CD4+ cells (Fig. 4a). At 14 dpo, microglia in the axotomized FMNuc became reactive as evidenced by increased expression of 


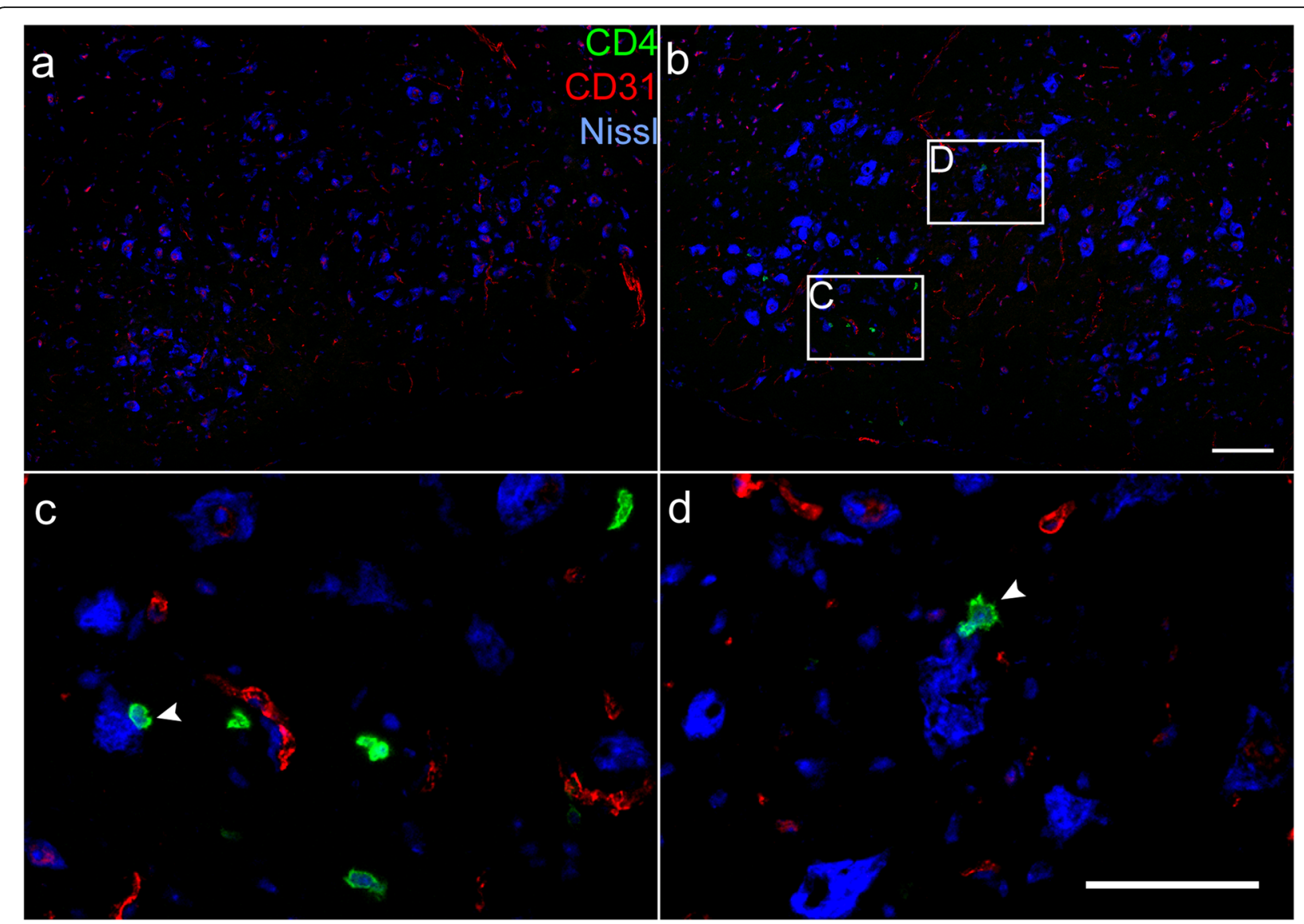

Fig. $3 \mathrm{HC}$ of CD4+ T cells (green) and CD31-labeled endothelial layer of blood vessels (red) penetrating the FMNuc. a Composite image of control FMNuc at 14 dpo showing no infiltrating T cells. b Composite image of axotomized FMNuc at 14 dpo. c, d Magnified fields from boxes in b showing CD4+ $T$ cells are not contained within CD31-labeled blood vessels. Note, CD4+ T cells marked with arrowheads in close proximity to FMN labeled with fluorescent Nissl stain (blue). Scale bar in $\mathbf{b}=100 \mu \mathrm{m}$ and applies to $\mathbf{a}$ and $\mathbf{b}$. Scale bar in $\mathbf{d}=50 \mu \mathrm{m}$ and applies to $\mathbf{c}$ and $\mathbf{d}$

IBA1, and a CD4+ T cell infiltrate was observed (Fig. 4b). These CD4+ T cells often appeared to be clustered around reactive microglial nodules (Fig. $4 \mathrm{c}-\mathrm{h}$, arrowheads).

To determine whether the adaptive immune system has an effect on central upregulation of the IL-10R after axotomy, qPCR was performed for IL-10R subunit gene expression in the FMNuc of WT, immunodeficient, and immune-cell reconstituted mice. Gene expression was calculated as fold change of mRNA expression in axotomized FMNuc relative to control FMNuc. Fold change in Il10ra expression (Fig. 5a) was significantly reduced in RAG- $2^{-1-}$ $(3.97 \pm 0.26)$ compared to WT $(5.70 \pm 0.35, p<0.05)$ and was restored to WT levels after adoptive transfer of WT $\mathrm{CD} 4+\mathrm{T}$ cells $(6.12 \pm 0.38)$. Fold change in Il10rb expression (Fig. 5b) was likewise significantly reduced in RAG$2^{-/-}(2.06 \pm 0.10)$ compared to WT $(2.74 \pm 0.15, p<0.01)$, and adoptive transfer of WT CD4+ T cells restored normal Il10rb expression $(2.74 \pm 0.07)$. These data indicate that $\mathrm{CD} 4+\mathrm{T}$ cells are necessary for full upregulation of IL-10R subunits in the FMNuc after axotomy.
This regulation of IL-10R expression by CD4+ T cells could be due to $\mathrm{T}$ cell-triggered induction of IL-10R expression on CNS resident cells and/or infiltration of IL10R-expressing $\mathrm{T}$ cells into the FMNuc after axotomy. To elucidate which scenario occurs after FNA, RAG- ${ }^{-1-}$ mice were reconstituted with $\mathrm{CD} 4+\mathrm{T}$ cells lacking Il10rb expression, which is necessary for IL-10 signal transduction [32, 33]. Il10ra fold change in RAG- ${ }^{-1-}$ mice reconstituted with Il1Orb $^{-1-}$ CD4+ T cells (Fig. 5a, $7.54 \pm 0.65$ ) was significantly increased relative to RAG- $2^{-1-}(p<0.001)$, indicating that IL-10 signaling within T cells was not necessary for T cells to regulate Il10ra gene expression in the FMNuc. In fact, upregulation of Il1Ora in RAG-2 ${ }^{-1-}$ mice given IllOr $\mathrm{rb}^{-1-}$ $\mathrm{CD} 4+\mathrm{T}$ cells was significantly greater than in WT or RAG-2 ${ }^{-1-}$ given WT CD4+ T cells $(p<0.05)$, perhaps due to a compensatory reaction in the FMNuc. Il10rb fold change in RAG-2 ${ }^{-1-}$ reconstituted with $I l 10 \mathrm{rb}^{-1-} \mathrm{CD} 4+\mathrm{T}$ cells (Fig. 5b, $2.64 \pm 0.09$ ) was significantly increased relative to RAG- $2^{--}(p<0.001)$ and was not significantly different from WT or RAG-2 ${ }^{-1-}+$ WT CD4+ T cells. Due to 


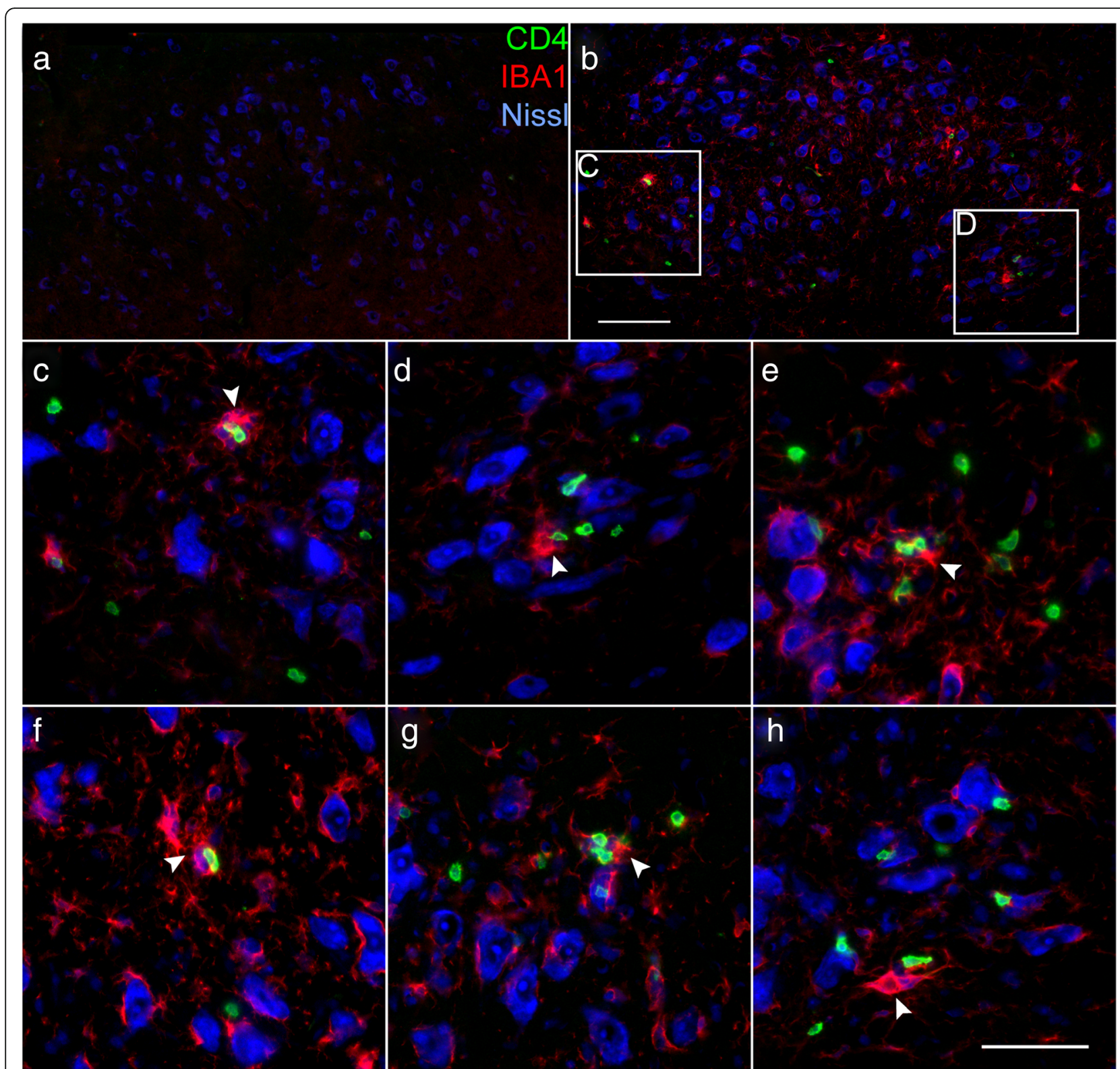

Fig. $4 \mathrm{HC}$ of CD4+ T cells (green) and IBA+ microglia (red) in the FMNuc. Nissl-labeled neurons are shown in blue. a Composite image of control FMNuc at 14 dpo showing no infiltrating T cells or reactive IBA+ microglia. b Composite image of axotomized FMNuc at 14 dpo. c, d Magnified fields from boxes in $\mathbf{b}$ showing IBA1+ microglial nodules (arrowheads) with associated CD4+ T cells. $\mathbf{e}-\mathbf{h}$ Representative fields from axotomized FMNuc in other experimental animals showing IBA1+ microglial nodules (arrowheads) with associated CD4+ T cells. Scale bar in $\mathbf{b}=100 \mu \mathrm{m}$ and applies to $\mathbf{a}$ and $\mathbf{b}$. Scale bar in $\mathbf{h}=50 \mu \mathrm{m}$ and applies to $\mathbf{c}-\mathbf{h}$

absence of Il10rb expression by the transgenic T cells, this restoration of Il1Orb gene expression could only be due to a T cell-mediated induction of Il10rb in CNS resident cells in the FMNuc.

Although it was found that $1110 \mathrm{rb}^{-1-} \mathrm{CD} 4+\mathrm{T}$ cells were capable of triggering an increase in IL-10R expression by CNS resident cells in the FMNuc, the neuroprotective capacity of these $\mathrm{T}$ cells remained unknown. It is well established in the literature that RAG- $2^{-1-}$ mice exhibit decreased FMN survival after axotomy relative to WT, and that WT CD4+ T cells restore FMN survival in RAG-2 ${ }^{-1-}$ mice to WT levels $[2,3]$. The ability of $I l 10 \mathrm{rb}^{-1-} \mathrm{CD} 4+\mathrm{T}$ cells to mediate neuroprotection was assayed by quantifying FMN survival in WT, RAG- $2^{-1-}$, and RAG- $2^{-1-}$ reconstituted with $I l 10 \mathrm{rb}^{-1-} \mathrm{CD} 4+\mathrm{T}$ cells at $28 \mathrm{dpo}$. In accordance with the literature, survival in RAG-2 ${ }^{-1-}$ was significantly decreased compared to WT (Fig. 6a, $69 \pm 1.3 \%$ compared to $81 \pm 3 \%, p<0.05)$. However, Il10rb ${ }^{-1-} \mathrm{CD} 4+\mathrm{T}$ cells failed to rescue FMN survival; survival in reconstituted animals remained low compared to WT $(61.8 \pm 3.5 \%, p<0.01)$. To 

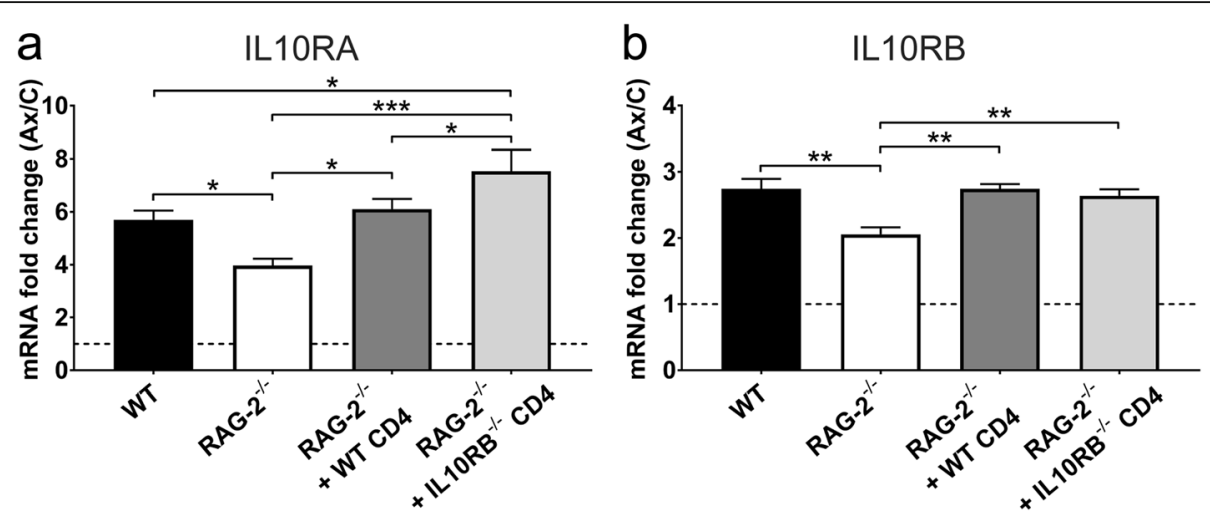

Fig. 5 mRNA fold change of $\mathbf{a} \| 10 \mathrm{ra}$ and $\mathbf{b} \| 10 \mathrm{rb}$ in the axotomized FMNuc relative to control FMNuc at 14 days post-FNA in WT, RAG-2/-, RAG$2^{-1-}+$ WT CD4+ T cells, and RAG- $2^{-1-}+1110 \mathrm{rb}^{-1-} \mathrm{CD} 4+\mathrm{T}$ cells. Bars represent mean fold change \pm SEM. Dotted line represents baseline level of gene expression in control FMNuc. ${ }^{*} p<0.05,{ }^{* *} p<0.01,{ }^{* * *} p<0.001$

confirm that adoptively transferred $\mathrm{Il10 \textrm {rb }}{ }^{-1-} \mathrm{T}$ cells were still viable in vivo at $28 \mathrm{dpo}$, IHC was performed using spleens from WT, RAG- ${ }^{-/-}$, and RAG-2 ${ }^{-1-}$ mice reconstituted with IllOrb $^{-1-} \mathrm{CD} 4+\mathrm{T}$ cells. WT spleens contained $\mathrm{CD} 3+\mathrm{T}$ cell follicles that were absent in RAG-2 ${ }^{-1-}$ spleen and restored in RAG- $2^{-1-}$ given $I l 10 \mathrm{rb}^{-1-} \mathrm{CD} 4+\mathrm{T}$ cells (Fig. $6 \mathrm{~b}, \mathrm{c})$, indicating that transferred cells successfully engrafted into host lymphoid tissue. Overall, these data suggest that the increase in IL-10R expression by
CNS resident cells, although mediated by $\mathrm{T}$ cells, is insufficient for FMN survival after FNA; rather, IL$10 \mathrm{R}$ signaling by the $\mathrm{T}$ cell itself may be necessary for neuroprotection.

To investigate the role of T cell IL-10R signaling in modulating central APC activation after FNA, qPCR for genes associated with microglial activation, antigen presentation, $\mathrm{T}$ cell co-stimulation, and complement deposition/synaptic pruning was performed in the FMNuc of WT, RAG-2 ${ }^{-1}$,
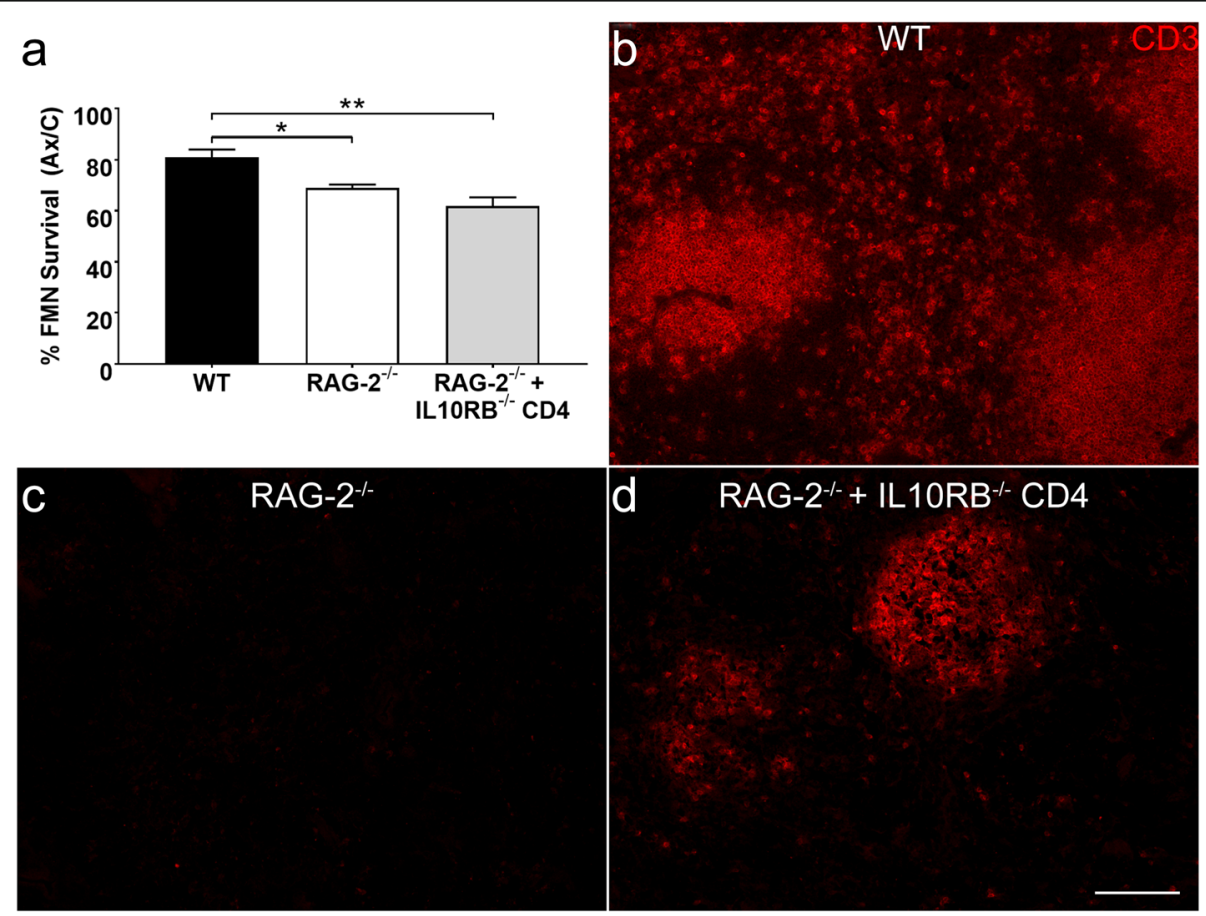

Fig. 6 a Average percent survival of axotomized FMN relative to control \pm SEM at 28 dpo in WT, RAG- $2^{-/}$, and RAG-2/- reconstituted with $/ / 10 b^{-1-}$ CD4+ T cells. Survival in both RAG-2 ${ }^{-1-}$ and $\mathrm{RAG}^{-/-}$reconstituted with $/ 110 \mathrm{rb}^{-1-} \mathrm{CD} 4+\mathrm{T}$ cells was decreased relative to WT, indicating that $/ 110 \mathrm{rb}{ }^{-1-}$ T cells fail to confer neuroprotection. ${ }^{*} p<0.05,{ }^{* *} p<0.01$. b IHC showing CD3+ T cells in WT splenic follicles. c CD3+ cells are absent in RAG-2 ${ }^{-1-}$ spleens. $\mathbf{d}$ Adoptive transfer of $/ 11 \mathrm{Orb}^{-1-} \mathrm{CD} 4+\mathrm{T}$ cells restores CD3+ expression in splenic follicles, indicating that $/ 110 \mathrm{rb}{ }^{-/-}$CD4+ T cells were successfully transplanted and remain viable in vivo until $28 \mathrm{dpo}$. Scale bar $=100 \mu \mathrm{m}$ and applies to $\mathbf{b}-\mathbf{d}$ 
and $\mathrm{RAG}^{-1-}$ mice reconstituted with either WT or Il10 $\mathrm{rb}^{-1-}$ CD4+ T cells. The hypothesis was that loss of IL-10 receptor signaling on $\mathrm{T}$ cells would promote a pro-inflammatory, autoimmune-reactive microglial/macrophage gene signature in the FMNuc.

Cd68, Cd40, Tnf, and Nos2 were genes selected for evaluation of general microglial pro-inflammatory activation. At 14 dpo, Cd68 mRNA increased approximately sixfold in the WT axotomized FMNuc; there was no difference in Cd68 expression between WT, RAG- $2^{-1-}$, and RAG-2 ${ }^{-/-}$ mice reconstituted with WT CD4+ T cells (Fig. 7a, $6.078 \pm$ $0.88,5.809 \pm 0.25,6.785 \pm 0.29$, respectively). RAG- $2^{-/-}$ mice reconstituted with $1 l 10 \mathrm{rb}^{-1-} \mathrm{CD} 4+\mathrm{T}$ cells had significantly increased $C d 68$ expression in the axotomized FMNuc $(9.37 \pm 0.69)$ relative to WT $(p<0.01)$, RAG- ${ }^{-1}$, and RAG- $2^{-1-}+$ WT CD4+ T cells $(p<0.05)$, indicating that $1 l 10 \mathrm{rb}^{-1-} \mathrm{T}$ cells promote an increase in general microglial reactivity after axotomy. $C d 40$ mRNA was modestly increased in the axotomized FMNuc relative to control across all conditions, and there were no significant differences between WT, RAG-2 ${ }^{-/}$, and RAG- ${ }^{-1-}+$ IllOrb $^{-1-}$ CD4+ T cells (Fig. 7b, $1.57 \pm 0.11,1.46 \pm 0.08,2.17 \pm 0.24$, respectively). There was also no significant difference between RAG- $2^{-1-}$ mice reconstituted with WT CD4+ T cells $(2.40 \pm 0.25)$ and those reconstituted with $I l 10 r b^{-1-} \mathrm{CD} 4+\mathrm{T}$ cells, although the former showed significantly increased $C d 40$ expression relative to WT and RAG- $2^{-1-}(p<0.05)$.

No Tnf transcript was detected in the control FMNuc, in agreement with previous studies $[5,34]$. Therefore, to compare changes in $\operatorname{Tn} f$ mRNA expression, the differences between Tnf and Gapdh cycle threshold values were normalized to the same standardized spleen control for each axotomized FMNuc sample. As shown in Fig. 7c, Tnf mRNA in axotomized FMNuc at 14 dpo ranged between $1-3 \%$ of spleen standard, and no differences were observed between WT, RAG- $2^{-1-}$, RAG- $2^{-1-}+$ WT CD $4+$ T cell, and $\mathrm{RAG}^{-1-}+$ Ill10rb $^{-1-} \mathrm{CD} 4+\mathrm{T}$ cell groups $(0.015 \pm 0.003$, $0.017 \pm 0.004,0.024 \pm 0.005,0.023 \pm 0.004$, respectively). Nos 2 mRNA did not appear to be upregulated in the axotomized FMNuc and in fact may have slightly decreased relative to control in WT and RAG- ${ }^{-1-}$ mice receiving $I l 10 \mathrm{rb}^{-1-}$ CD4 $+\mathrm{T}$ cells (Fig. 7d, results of one-sample $t$ test against fold change of 1 : WT, $0.76 \pm 0.05, p=0.008$; RAG- $2^{-1-}+$ Il10 $\left.\mathrm{rb}^{-1-} \mathrm{CD} 4,0.71 \pm 0.09, p=0.033\right)$. There were no significant differences detected between these groups and RAG$2^{-/-}$mice or RAG- $2^{-/-}+$WT CD $4+$ T cells $(0.87 \pm 0.17$ and $0.78 \pm 0.11$, respectively).

$H 2 a b 1$ and $C d 86$ were selected for analysis of microglial antigen presentation and $\mathrm{T}$ cell co-stimulation-associated gene expression in the axotomized FMNuc. H2ab1 encodes
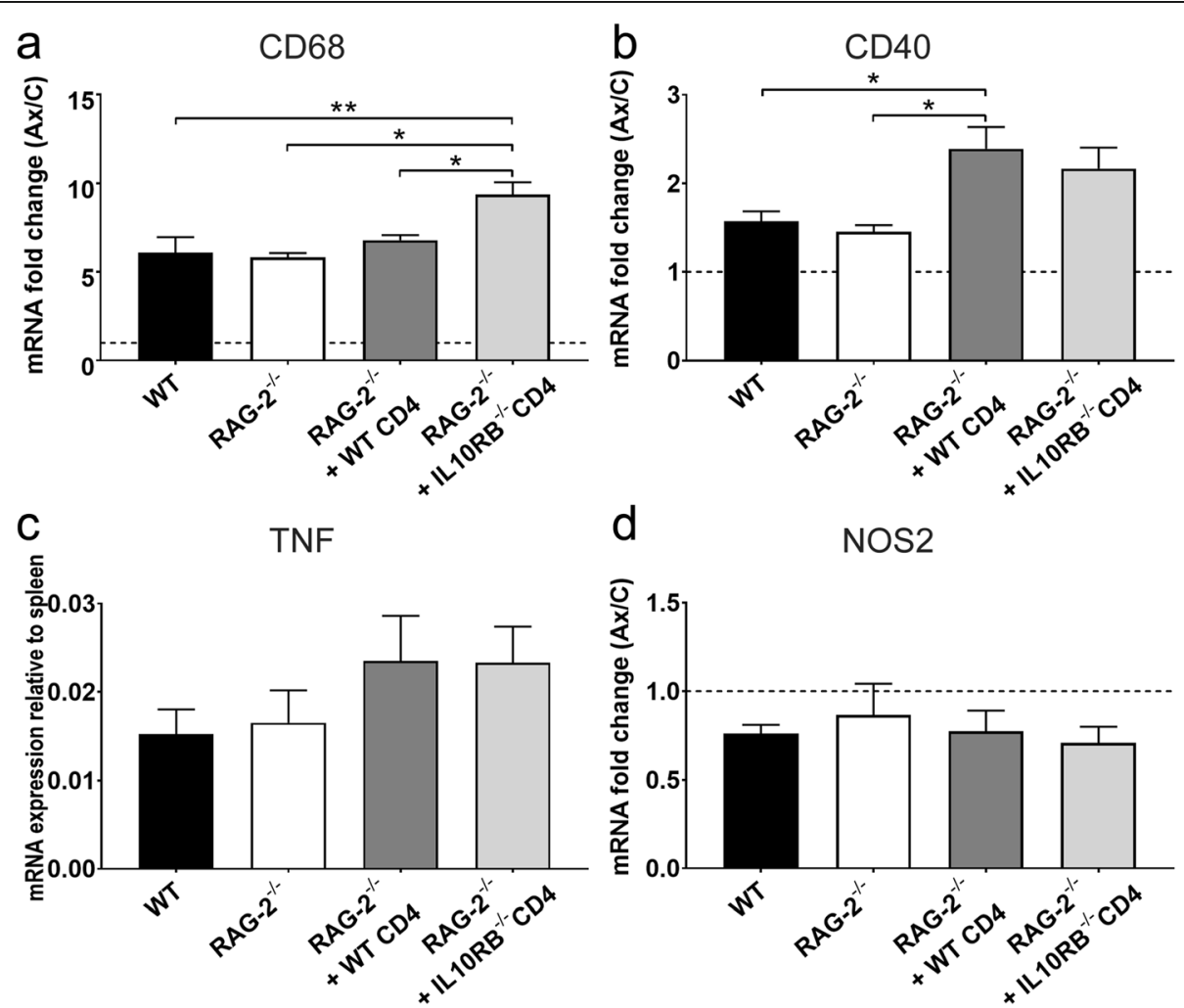

Fig. 7 mRNA fold change of a CD68, b Cd40, c Tnf, and $\mathbf{d}$ Nos2 in the axotomized FMNuc relative to control FMNuc (except for Tnf, which is relative to spleen control) at 14 days post-FNA in WT, RAG- $2^{-1}$, RAG- $2^{-1-}+W T$ CD4+ T cells, and RAG- $2^{-1-}+\| 10 r b^{-1-}$ CD4+ T cells. Bars represent mean fold change \pm SEM. ${ }^{*} p<0.05,{ }^{* *} p<0.01$ 

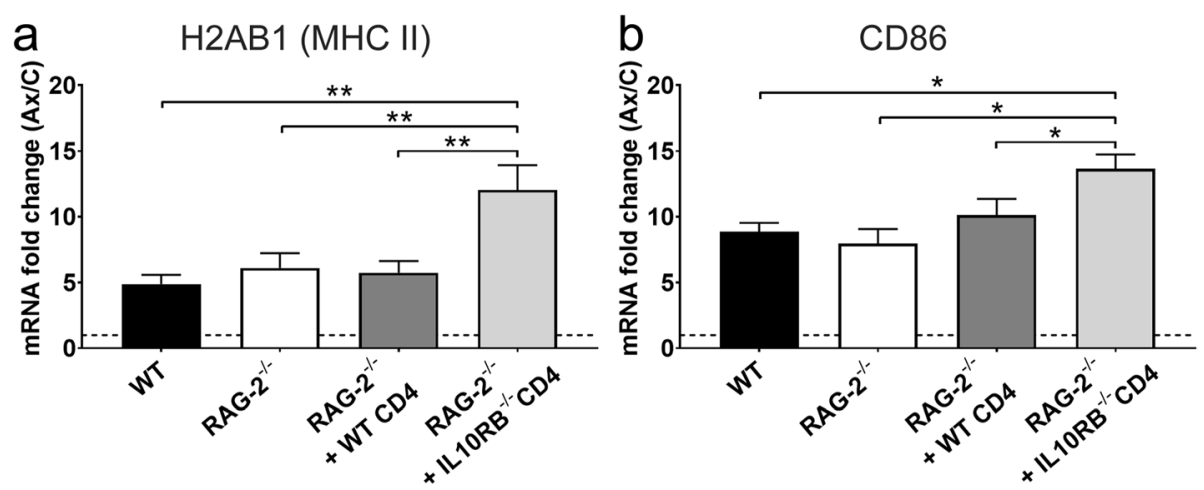

Fig. 8 mRNA fold change of a H2ab1 and $\mathbf{b}$ Cd86 in the axotomized FMNuc relative to control FMNuc at 14 days post-FNA in WT, RAG- ${ }^{-1}$, RAG-

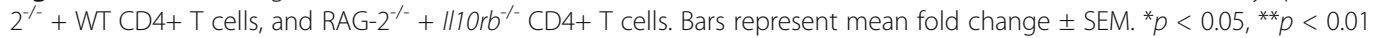

the predominant MHC class II haplotype expressed in C57BL/6 J mice, and CD86 is a co-stimulatory molecule expressed by microglia that interacts with CD28 on T cells. Axotomy robustly induced $H 2 a b 1$ in WT animals; expression increased approximately fivefold relative to control FMNuc (Fig. 8a). RAG- ${ }^{-1-}$ mice that received adoptive transfer of Il1Orb ${ }^{-1-} \mathrm{CD} 4+\mathrm{T}$ cells exhibited dramatically higher induction of $H 2 a b 1$ expression after axotomy compared to WT, RAG-2 ${ }^{-/}$, and RAG- ${ }^{-1-}+$ WT CD4+ T cells $(12.5 \pm 1.88$ vs. $4.9 \pm 0.71,6.1 \pm 1.12,5.8 \pm 0.89$, respectively; $p<0.01$ ). Expression of $C d 86$ also increased robustly in response to axotomy with approximate 9-fold induction in WT (Fig. 8b). RAG-2 ${ }^{-1-}$ mice given Il10rb ${ }^{-1-}$ CD4+ T cells exhibited significantly increased expression of $C d 86$ after axotomy compared to WT, RAG- $2^{-1-}$, and RAG- $2^{-1-}+$ WT CD4+ T cells $(13.7 \pm 1.10$ vs. $8.9 \pm 0.67,7.9 \pm 1.13,10.1 \pm$ 1.24 , respectively, $p<0.05$ ).

Both MHC class I and C3 are associated with microglial phagocytic nodule formation and synaptic pruning [16, $35-37]$. $B 2 m$ encodes the MHC class I subunit $\beta 2-$ microglobulin. $B 2 m$ mRNA expression increased fivefold in the WT axotomized FMNuc and was not significantly different in RAG-2 ${ }^{-1-}$ mice (Fig. 9a, $5.0 \pm 0.28,7.2 \pm 0.85$, respectively). Adoptive transfer of WT CD4+ T cells into RAG- $2^{-/-}$mice resulted in significantly increased $B 2 m$ expression relative to WT and RAG-2 ${ }^{-1-}\left(\mathrm{RAG}^{-1-}+\mathrm{WT}\right.$ CD4 $11.0 \pm 1.02$ vs. WT, $p<0.001$; vs. RAG- $2^{-1-}, p<0.01$ ). RAG-2 $^{-1-}$ mice given Il10 $\mathrm{rb}^{-1-} \mathrm{CD} 4+\mathrm{T}$ cells had significantly increased expression of $B 2 m$ after axotomy compared to WT, RAG-2 ${ }^{-1}$, and RAG-2 ${ }^{-1-}+$ WT CD4+ T cells $\left(\mathrm{RAG}^{-1-}+\mathrm{Il1Orb}^{-1-} \mathrm{CD} 414.9 \pm 0.81\right.$ vs. WT and RAG$2^{-1-}, p<0.0001$; vs. RAG- $2^{-1-}+$ WT CD4, $\left.p<0.01\right)$. C3 mRNA increased modestly in the FMNuc of WT mice after axotomy and was not significantly different in RAG- $^{-1-}$ mice (Fig. 9b, $2.6 \pm 0.39,0.9 \pm 0.35$, respectively). Adoptive transfer of WT $\mathrm{CD} 4+\mathrm{T}$ cells into RAG- $2^{-1-}$ mice resulted in increased $C 3$ expression (5.3 \pm 1.24 vs. WT, $p<0.05$; vs. RAG- $2^{-1-}, p<0.01$ ). Adoptive transfer of $I l 10 \mathrm{rb}^{-1-} \mathrm{CD} 4+\mathrm{T}$ cells resulted in even greater $C 3$ expression than in WT, RAG- $2^{-1-}$, or RAG$2^{-/-}+$WT CD $4+$ T cells $(9.4 \pm 0.86$ vs. WT and RAG$2^{-1-}, p<0.0001$; vs. RAG- $2^{-1-}+$ WT CD $\left.4, p<0.01\right)$.

Flow cytometry was utilized to determine whether loss of IL-10RB affects $\mathrm{T}$ cell subset differentiation. Both
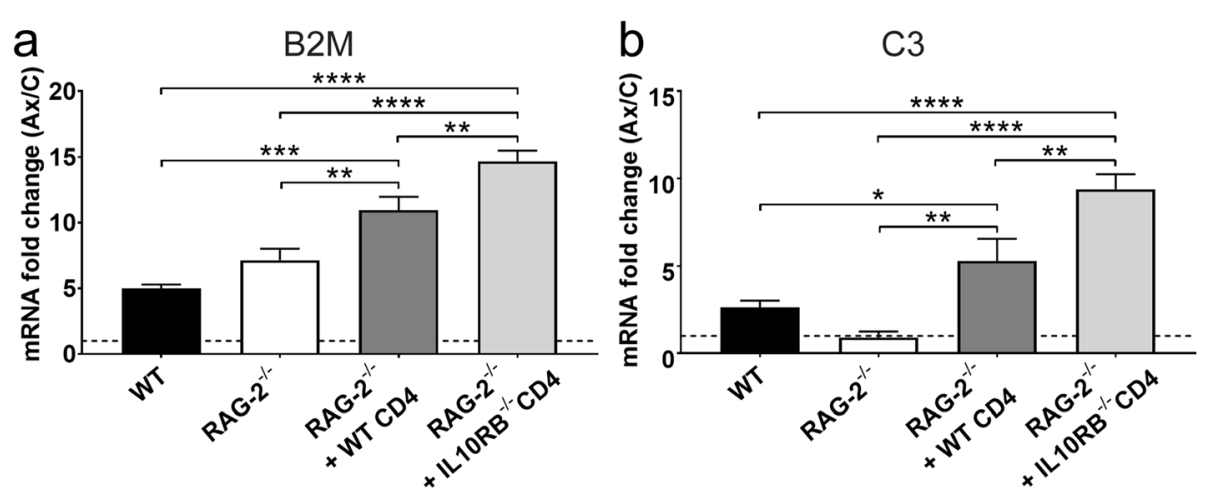

Fig. 9 mRNA fold change of $\mathbf{a} B 2 m$ and $\mathbf{b} C 3$ in the axotomized FMNuc relative to control FMNuc at 14 days post-FNA in WT, RAG- ${ }^{-1 /}$, RAG- $2^{-1-}+$ WT CD4+ T cells, and RAG-2 ${ }^{-1}+1 / 10 \mathrm{rb}^{-/-}$CD4+ T cells. Bars represent mean fold change \pm SEM. ${ }^{*} p<0.05,{ }^{* *} p<0.01,{ }^{* * *} p<0.001,{ }^{* * * *} p<0.0001$ 
unstimulated and in vitro stimulated splenocytes from WT and $1 l 10 \mathrm{rb}^{-1-}$ mice were included as groups for statistical analysis; in Fig. 10, only data from stimulated cells are shown. Baseline (unstimulated) numbers of cells within $\mathrm{T}$ cell subsets did not differ between WT and $I l 10 \mathrm{rb}^{-1-}$ splenocytes and whether expressed as percent within the overall CD4+ T cell population or as absolute cell counts (data available upon request). After stimulation, there were no differences between WT and Il10 $\mathrm{rb}^{-1-}$ in populations of Th1 (Fig. 10a, $9.14 \pm 0.92 \%$ vs. $7.84 \pm$ $1.22 \%$; $41 \pm 6.81$ vs. $35 \pm 7.54$ ), Th2 (Fig. 10b, $55.8 \pm$ $1.46 \%$ vs. $53.77 \pm 0.72 \% ; 1003 \pm 158.8$ vs. $748 \pm 73.51$ ), or Th17 cells (Fig. 10c, $57.17 \pm 2.89 \%$ vs. $63.43 \pm 13.82 \%$; $1072 \pm 209.3$ vs. $709 \pm 85.85$ ). There was a small but significant reduction in Tregs in $1110 \mathrm{rb}^{-1-}$ compared to WT splenocytes when analyzed as percent within $\mathrm{CD} 4+\mathrm{T}$ cell population (Fig. 10d, $77.93 \pm 1.22 \%$ in $I l 10$ rb $^{-1-}$ vs. $84.5 \pm$ $1.76 \%$ in WT, $p<0.05)$ as well as absolute cell counts $\left(550 \pm 71.01\right.$ in $^{2 l 10 \mathrm{rb}^{-1-}}$ vs. $771 \pm 110.6$ in WT, $\left.p<0.05\right)$.

\section{Discussion}

This study demonstrates that $\mathrm{CD} 3+\mathrm{CD} 4+\mathrm{T}$ cells are indeed capable of crossing the blood-brain barrier into the FMNuc parenchyma after axotomy, where they may interact directly with CNS resident cells. It is therefore possible that immune-mediated neuroprotection and other central molecular responses to axotomy influenced by peripheral immune status are effected by local paracrine signaling from infiltrating $\mathrm{T}$ cells or by direct contact between $\mathrm{T}$ cells and CNS resident cells in the FMNuc. We demonstrate that $\mathrm{CD} 4+\mathrm{T}$ cells often localize with microglial nodules, which is in agreement with other studies finding accumulation of CD3+ cells near microglial clusters after FNA [11, 28]. Microglial nodules in the FMNuc are associated with phagocytosis of dead neurons and are characterized by strong MHC class II immunoreactivity, making them potential "hotspots" for presentation of neuronal antigen and activation of infiltrating $\mathrm{T}$ cells $[28,29]$.

A previous study from our laboratory showed that both IL-10 and CD4+ T cells are necessary for FMN survival, but CD4+ T cells are not a required source of IL-10 in the FNA injury model. Interestingly, RAG- $2^{-1-}$ mice have transiently depressed IL-10 levels in the FMNuc during the early post-injury phase which are restored by CD4+ T cell reconstitution [19]; however, this effect is modest, resolves quickly, and occurs prior to significant central $\mathrm{T}$ cell infiltration as described by others $[11,28]$. Although it is still possible that maintenance of IL-10 expression by CNS resident cells is one mechanism by which $\mathrm{CD} 4+\mathrm{T}$ cells

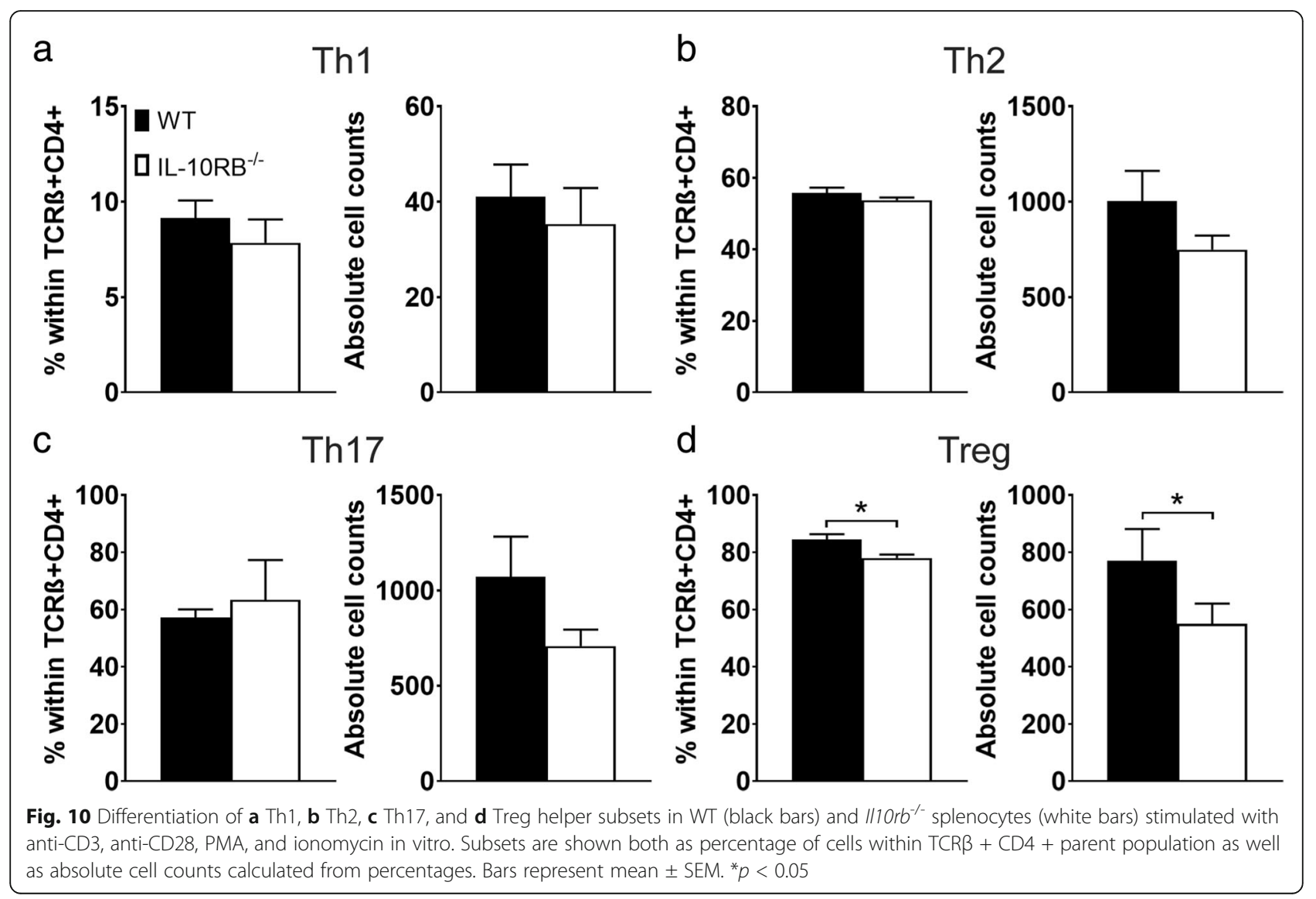


support FMN survival, further investigation into a potential link between IL-10-mediated and adaptive immunemediated mechanisms of neuroprotection was warranted. The data in this study expand our knowledge of the requirements for both IL-10 and CD4+ T cells in the injured FMNuc. Because overall levels of IL-10 in the FMNuc do not change in response to axotomy in the WT animal [19], induction of neuroprotective IL-10 signaling depends on increased IL-10R expression, likely on neurons and/or astrocytes $[19,28]$. CD4+ T cells may be necessary for full induction of neuroprotective IL-10 signaling by triggering upregulation of IL-10R gene expression in the FMNuc, regardless of their own IL-10RB expression or IL-10 signaling capability. A recent study on immune-mediated neuroprotection in the context of chemotherapy-induced peripheral neuropathy (CIPN) bears striking similarities with our observations after FNA. Krukowski et al. demonstrated that CD8+ T cells and IL-10 are necessary for recovery of normal sensation after CIPN; however, the $\mathrm{T}$ cell is not the requisite source of IL-10. Rather, the presence of CD8+ T cells is necessary for upregulation of Il10ra mRNA in dorsal root ganglion neurons after paclitaxel-induced injury [38]. These data support a role for $\mathrm{T}$ cell regulation of the IL-10 signaling cascade via induction of IL-10R expression on neurons after peripheral nerve injury.

IL-10 has direct trophic effects on neurons, of which various populations have been shown to express IL-10R in vivo and in vitro $[18,19,28,39,40]$. Application of exogenous IL-10 to primary cortical neurons undergoing oxygen-glucose deprivation challenge suppresses apoptosis, promotes neurite outgrowth, and enhances synaptogenesis [39]. In cultured spinal cord neurons, IL-10R activation prevents glutamate-induced excitotoxicity [18]. Exogenous IL-10 treatment also improves neuron survival in vivo after spinal cord injury through regulation of pro- and anti-apoptotic factors [41]. An increase in neuronal IL-10R expression mediated by CD4+ T cells may therefore have an important role in trophic support for injured motoneurons after axotomy. The proposal that these trophic signals must arrive centrally via IL-10R signaling on the neuron cell body is congruent with a previous finding from our laboratory which showed that application of exogenous IL-10 to the peripheral nerve stump fails to restore neuron survival in either $\mathrm{IL}-10^{-1-}$ or RAG- $2^{-1-}$ mice [19]. Future studies will investigate the effects of selective application of IL-10 to the central compartment after axotomy.

Despite regulating IL-10R gene expression on other cells normally, $\mathrm{T}$ cells that are unresponsive to IL-10 themselves via loss of the IL-10RB subunit fail to confer neuroprotection after axotomy. Although IL-10RB is considered a promiscuous receptor subunit that is shared with some interferon receptors and other IL-10 family cytokines, cells lacking IL-10RB respond normally to both type I interferons and IFNy, but are completely unresponsive to IL-10 [32, 33, 42]. Loss of IL-10RB alone is sufficient to recapitulate the auto-inflammatory intestinal pathology observed in IL-10 $0^{-1-}$ animals [33]. IL-10 directly inhibits CD28 phosphorylation in $\mathrm{T}$ cells and induces $\mathrm{T}$ cell anergy [43-47]. This loss of tolerance to self-antigen after axotomy in Il10r- ${ }^{-1-} \mathrm{CD} 4+\mathrm{T}$ cells could be the cause for their failure to mediate neuroprotection.

Tolerized T cells actively suppress APCs by downregulating their expression of the antigen presentation and costimulation molecules MHC class II, CD80, and CD86 [22]. Low CD86 is associated with tolerogenic APCs and an anti-inflammatory microglia phenotype [48-51], whereas increased microglial MHC class II and CD86 are associated with neurodegenerative and autoimmune conditions [5255]. The Il10rb ${ }^{-1-} \mathrm{CD} 4+\mathrm{T}$ cells utilized in this study promoted greater expression of $\mathrm{Cd} 68, \mathrm{H} 2 \mathrm{ab1}$, and $\mathrm{Cd} 86$, suggesting that they may enhance microglial activation, antigen presentation, and T cell co-stimulation. Loss of IL10 signaling in $\mathrm{CD} 4+\mathrm{T}$ cells may dis-inhibit a deleterious autoimmune response mediated by microglia after injury.

MHC class I immunoreactivity is highly specific to microglial phagocytic nodule formation in the injured FMNuc $[15,16]$. FNA also activates microglial expression of $C 3$ mRNA and the C3 receptor [56-58]. High complement, including $\mathrm{C} 3$, and exaggerated synaptic pruning are associated with neuronal death in CNS disease and injury [59-66]. Il1Orb ${ }^{-1-}$ CD4+ T cells promoted expression of both $B 2 m$ and $C 3$, implicating $T$ cells as modulators of microglial phagocytosis and synaptic pruning. Because synapse elimination can be either destructive or protective by shielding injured FMN from excitotoxic inputs [67], the modest increase in $B 2 m$ and $C 3$ caused by WT CD4+ $\mathrm{T}$ cells in this study may represent a "Goldilocks zone" for beneficial synaptic elimination after FNA. However, the greater increases in $B 2 m$ and $C 3$ observed after transfer of Il10rb ${ }^{-1-} \mathrm{CD} 4+\mathrm{T}$ cells suggest that increased synaptic elimination (or perhaps phagocytosis of stressed neurons) may enhance neuronal death after axotomy.

Other studies have demonstrated the importance of IL10R signaling specifically in $\mathrm{T}$ cells. Adoptive transfer of CD4+ T cells overexpressing a dominant-negative form of IL-10RA into immunodeficient mice causes the development of spontaneous enterocolitis [68]. In mouse models and in humans, $\mathrm{T}$ cells nonresponsive to IL-10 escape Treg control, proliferate to a greater degree, and produce higher amounts of inflammatory cytokines such as Th17 and IFNy, both of which activate macrophages and promote cellular autoimmunity [68, 69]. Interestingly, IL-10R signaling and downstream STAT3 phosphorylation are defective in $\mathrm{CD} 4+\mathrm{T}$ cells from patients with systemic lupus erythematosus and MS, suggesting that failure of $\mathrm{T}$ cell suppression by IL-10 may play an important role in autoimmune disease, including in the CNS [70, 71]. 
The harmful role of autoreactive $\mathrm{T}$ cells is supported by studies finding that immunization with or without neural antigen exacerbates motoneuron loss after spinal cord injury and FNA, indicating an overall detrimental effect of enhancing adaptive immune reactivity on neuron survival $[72,73]$. Those findings, as well as those described in this study, initially appear to contradict previous results from our laboratory that $\mathrm{T}$ cells must encounter MHC class II both peripherally and centrally in order to confer neuroprotection after axotomy [6]. However, high MHC class II expression in the absence of adequate co-stimulation may represent a mechanism by which microglia attempt to terminate autoreactive $\mathrm{T}$ cell responses [74]. Therefore, the requirement for dual compartment MHC class II expression for neuroprotection may actually represent the need for deletion of certain autoreactive $\mathrm{T}$ cell populations after axotomy.

The failure of Il1Orb $^{-1-} \mathrm{CD} 4+\mathrm{T}$ cells to promote neuroprotection also prompted the hypothesis that loss of IL-10 signaling may result in failure of differentiation of the neuroprotective Th2 subtype. Surprisingly, the numbers of Th1, Th2, and Th17 cells were not affected by loss of IL10RB, but a decrease in the Treg population was observed. Although natural Tregs have been previously ruled out as important for neuroprotection after FNA [75], these data suggest that inducible Tregs (iTregs) may have a neuroprotective role after axotomy that is dependent on intact IL-10 signaling. However, it is important to note that interpretation of this study is limited, as $\mathrm{T}$ cell differentiation was elicited by non-specific stimulation of splenocytes in vitro rather than by FNA-associated antigen displayed on APCs. Furthermore, it is possible that $I l 10 \mathrm{rb}^{-/} \mathrm{CD} 4+\mathrm{T}$ cells become skewed toward a particular phenotype only after entering an inflammatory microenvironment in the axotomized FMNuc. It is becoming increasingly recognized that CD4+ T cell subsets do not necessarily represent terminally differentiated cell populations, but can demonstrate considerable plasticity depending on the cytokine microenvironment [76]. Future studies will evaluate the ability of adoptively transferred $I l 10 \mathrm{rb}^{-1-} \mathrm{CD} 4+\mathrm{T}$ cells to differentiate in vivo into $\mathrm{T}$ cell subsets (including iTregs) after FNA.

\section{Conclusions}

Neuroprotective CD4+ T cells infiltrate the FMNuc after axotomy and are required for full induction of central IL10R expression. CD4+ T cells lacking IL-10RB fail to confer neuroprotection after axotomy and promote a microglial gene signature associated with enhanced antigen presentation, $\mathrm{T}$ cell co-stimulation, and synaptic elimination. An autoimmune response to axotomy may also be exacerbated by decreased iTreg numbers in $I l 10 \mathrm{rb}^{-/-}$mice. These results suggest that although the degree of neuronal death in immunodeficient mice and mice reconstituted with $1110 \mathrm{rb}^{-1-}$ CD4+ T cells is comparable, the causes of FMN death are likely quite distinct. In immunodeficient mice, the neuroprotective Th2 subset is absent, and there is a blunted glial response to axotomy $[4,5]$. In contrast, mice given $I l 10 \mathrm{rb}^{-1-}$ $\mathrm{CD} 4+\mathrm{T}$ cells may exhibit dis-inhibition of a harmful autoimmune response that promotes microglial hyperresponsiveness to injury. In the spectrum of immune responses that can occur after axotomy, neither extreme is favorable, and optimum FMN survival likely depends on balanced activation of immune effectors.

\section{Abbreviations \\ APC: Antigen presenting cell; B2m: Beta-2 microglobulin; BBB: Blood-brain barrier; C3: Complement 3; CD: Cluster of differentiation; Dpo: Days post- operation; FMN: Facial motoneuron; FMNuc: Facial motor nucleus; FNA: Facial nerve axotomy; Gapdh: Glyceraldehyde 3-phosphate dehydrogenase; H2ab1: Histocompatibility 2, class II antigen A, beta 1; IBA1: Ionized calcium binding adaptor molecule 1; IL: Interleukin; IL-10R: Interleukin-10 receptor; MHC: Major histocompatibility complex; mRNA: Messenger ribonucleic acid; Nos2: Nitric oxide synthase 2; PBS: Phosphate buffered saline; \\ PFA: Paraformaldehyde; PMA: Phorbol 12-myristate 13-acetate; qPCR: Quantitative polymerase chain reaction; RAG-2: Recombinase activating gene 2; RT: Reverse transcription; Th: T helper; Treg: Regulatory $T$ cell; WT: Wild-type}

\section{Acknowledgements}

Not applicable.

\section{Authors' contributions}

EMR designed and performed experiments, analyzed the data, and drafted the manuscript. AKI designed the flow cytometry experiment and assisted with flow cytometry data acquisition and analysis. DOS assisted with GPCR experiments. FMK assisted flow cytometry. VMS and KJJ assisted with study concept and design and data interpretation. KJ provided study supervision and manuscript revision. The authors read and approved the final manuscript.

\section{Funding}

This work was supported by the National Institutes of Health, grant number NS40433 (KJJ and VMS).

\section{Availability of data and materials}

The datasets used and/or analyzed during the current study are available from the corresponding author on reasonable request.

\section{Ethics approval and consent to participate}

All animal procedures complied with the National Institutes of Health guidelines on the care and use of laboratory animals and were approved by the Institutional Animal Care and Use Committee at Indiana University School of Medicine.

\section{Consent for publication}

Not applicable.

\section{Competing interests}

The authors declare that they have no competing interests.

\section{Author details}

${ }^{1}$ Department of Anatomy, Cell Biology, and Physiology, Indiana University School of Medicine, 635 Barnhill Drive, Medical Science Building 5035, Indianapolis, IN 46202, USA. ${ }^{2}$ Research and Development, Richard L. Roudebush VA Medical Center, Indianapolis, IN, USA. ${ }^{3}$ Department of Neuroscience, Washington University School of Medicine, St. Louis, MO, USA. ${ }^{4}$ Department of Cancer Biology and Genetics, The Ohio State University, Columbus, $\mathrm{OH}, \mathrm{USA}$. 
Received: 7 November 2019 Accepted: 16 March 2020 Published online: 17 April 2020

\section{References}

1. Serpe CJ, Kohm AP, Huppenbauer CB, Sanders VM, Jones KJ. Exacerbation of facial motoneuron loss after facial nerve transection in severe combined immunodeficient (scid) mice. J Neurosci. 1999;19(11):RC7.

2. Serpe CJ, Sanders VM, Jones KJ. Kinetics of facial motoneuron loss following facial nerve transection in severe combined immunodeficient mice. J Neurosci Res. 2000;62(2):273-8.

3. Serpe CJ, Coers S, Sanders VM, Jones KJ. CD4+ T, but not CD8+ or B, lymphocytes mediate facial motoneuron survival after facial nerve transection. Brain Behav Immun. 2003;17(5):393-402.

4. Deboy CA, Xin J, Byram SC, Serpe CJ, Sanders VM, Jones KJ. Immunemediated neuroprotection of axotomized mouse facial motoneurons is dependent on the IL-4/STAT6 signaling pathway in CD4(+) T cells. Exp Neurol. 2006;201(1):212-24.

5. Setter DO, Runge EM, Schartz ND, Kennedy FM, Brown BL, McMillan KP, et al. Impact of peripheral immune status on central molecular responses to facial nerve axotomy. Brain Behav Immun. 2018;68:98-110.

6. Byram SC, Carson MJ, DeBoy CA, Serpe CJ, Sanders VM, Jones KJ. CD4positive $T$ cell-mediated neuroprotection requires dual compartment antigen presentation. J Neurosci. 2004;24(18):4333-9.

7. Wainwright DA, Xin J, Mesnard NA, Beahrs TR, Politis CM, Sanders VM, et al. Exacerbation of facial motoneuron loss after facial nerve axotomy in CCR3deficient mice. ASN Neuro. 2009;1(5):e00024

8. Wainwright DA, Mesnard NA, Xin J, Sanders VM, Jones KJ. Effects of facial nerve axotomy on Th2-associated and Th1-associated chemokine mRNA expression in the facial motor nucleus of wild-type and presymptomatic SOD1 mice. J Neurodegener Regen. 2009;2(1):39-44.

9. Wainwright DA, Xin J, Mesnard NA, Politis CM, Sanders VM, Jones KJ. Effects of facial nerve axotomy on Th2- and Th1-associated chemokine expression in the facial motor nucleus of wild-type and presymptomatic mSOD1 mice. J Neuroimmunol. 2009;216(1-2):66-75.

10. Petitto JM, Huang Z, Lo J, Streit WJ. IL-2 gene knockout affects T lymphocyte trafficking and the microglial response to regenerating facial motor neurons. J Neuroimmunol. 2003;134(1-2):95-103.

11. Raivich G, Jones LL, Kloss CU, Werner A, Neumann H, Kreutzberg GW. Immune surveillance in the injured nervous system: T-lymphocytes invade the axotomized mouse facial motor nucleus and aggregate around sites of neuronal degeneration. J Neurosci. 1998;18(15):5804-16.

12. Dauer DJ, Huang Z, Ha GK, Kim J, Khosrowzadeh D, Petitto JM. Age and facial nerve axotomy-induced $T$ cell trafficking: relation to microglial and motor neuron status. Brain Behav Immun. 2011;25(1):77-82.

13. Graeber MB, Tetzlaff W, Streit WJ, Kreutzberg GW. Microglial cells but not astrocytes undergo mitosis following rat facial nerve axotomy. Neurosci Lett. 1988;85(3):317-21.

14. Torvik A, Skjorten F. Electron microscopic observations on nerve cell regeneration and degeneration after axon lesions. II. Changes in the glial cells. Acta Neuropathol. 1971;17(3):265-82.

15. Streit WJ, Graeber MB, Kreutzberg GW. Peripheral nerve lesion produces increased levels of major histocompatibility complex antigens in the central nervous system. J Neuroimmunol. 1989;21(2-3):117-23.

16. Bohatschek M, Kloss CU, Hristova M, Pfeffer K, Raivich G. Microglial major histocompatibility complex glycoprotein-1 in the axotomized facial motor nucleus: regulation and role of tumor necrosis factor receptors 1 and 2. J Comp Neurol. 2004;470(4):382-99.

17. Lobo-Silva D, Carriche GM, Castro AG, Roque S, Saraiva M. Balancing the immune response in the brain: $\mathrm{LL}-10$ and its regulation. J Neuroinflammation. 2016;13(1):297.

18. Zhou Z, Peng $X$, Insolera R, Fink DJ, Mata M. Interleukin-10 provides direct trophic support to neurons. J Neurochem. 2009;110(5):1617-27.

19. Xin J, Wainwright DA, Mesnard NA, Serpe CJ, Sanders VM, Jones KJ. IL-10 within the CNS is necessary for CD4+ T cells to mediate neuroprotection. Brain Behav Immun. 2011;25(5):820-9.

20. Akdis CA, Blaser K. Mechanisms of interleukin-10-mediated immune suppression. Immunology. 2001;103(2):131-6.

21. Chai JG, Bartok I, Chandler P, Vendetti S, Antoniou A, Dyson J, et al. Anergic T cells act as suppressor cells in vitro and in vivo. Eur J Immunol. 1999;29(2):686-92.
22. Vendetti S, Chai JG, Dyson J, Simpson E, Lombardi G, Lechler R. Anergic T cells inhibit the antigen-presenting function of dendritic cells. J Immunol. 2000;165(3):1175-81.

23. Dasgupta S, Jana M, Liu X, Pahan K. Myelin basic protein-primed T cells induce nitric oxide synthase in microglial cells. Implications for multiple sclerosis. J Biol Chem. 2002;277(42):39327-33.

24. Murphy AC, Lalor SJ, Lynch MA, Mills KH. Infiltration of Th1 and Th17 cells and activation of microglia in the CNS during the course of experimental autoimmune encephalomyelitis. Brain Behav Immun. 2010;24(4):641-51.

25. Li J, Hsu HC, Mountz JD. The dynamic duo-inflammatory M1 macrophages and Th17 cells in rheumatic diseases. J Orthop Rheumatol. 2013;1(1):4.

26. Chen J, Wang W, Li Q. Increased Th1/Th17 responses contribute to lowgrade inflammation in age-related macular degeneration. Cell Physiol Biochem. 2017;44(1):357-67.

27. Olmstead DN, Mesnard-Hoaglin NA, Batka RJ, Haulcomb MM, Miller WM, Jones KJ. Facial nerve axotomy in mice: a model to study motoneuron response to injury. J Vis Exp. 2015;96:e52382.

28. Villacampa N, Almolda B, Vilella A, Campbell IL, Gonzalez B, Castellano B. Astrocyte-targeted production of IL-10 induces changes in microglial reactivity and reduces motor neuron death after facial nerve axotomy. Glia. 2015:63(7):1166-84.

29. Huang Z, Meola D, Petitto JM. Dissecting the effects of endogenous brain IL-2 and normal versus autoreactive T Iymphocytes on microglial responsiveness and T cell trafficking in response to axonal injury. Neurosci Lett. 2012;526(2):138-43.

30. Ha GK, Huang Z, Parikh R, Pastrana M, Petitto JM. Immunodeficiency impairs re-injury induced reversal of neuronal atrophy: relation to $T$ cell subsets and microglia. Exp Neurol. 2007;208(1):92-9.

31. Almolda B, Costa M, Montoya M, Gonzalez B, Castellano B. CD4 microglial expression correlates with spontaneous clinical improvement in the acute Lewis rat EAE model. J Neuroimmunol. 2009;209(1-2):65-80.

32. Kotenko SV, Krause CD, Izotova LS, Pollack BP, Wu W, Pestka S. Identification and functional characterization of a second chain of the interleukin-10 receptor complex. EMBO J. 1997;16(19):5894-903.

33. Spencer SD, Di Marco F, Hooley J, Pitts-Meek S, Bauer M, Ryan AM, et al. The orphan receptor CRF2-4 is an essential subunit of the interleukin 10 receptor. J Exp Med. 1998;187(4):571-8.

34. Haulcomb MM, Mesnard NA, Batka RJ, Alexander TD, Sanders VM, Jones KJ. Axotomy-induced target disconnection promotes an additional death mechanism involved in motoneuron degeneration in amyotrophic lateral sclerosis transgenic mice. J Comp Neurol. 2014;522(10):2349-76.

35. Schafer DP, Lehrman EK, Kautzman AG, Koyama R, Mardinly AR, Yamasaki R, et al. Microglia sculpt postnatal neural circuits in an activity and complement-dependent manner. Neuron. 2012;74(4):691-705.

36. Sabha M Jr, Emirandetti A, Cullheim S, De Oliveira AL. MHC I expression and synaptic plasticity in different mice strains after axotomy. Synapse. 2008;62(2):137-48.

37. Oliveira AL, Thams S, Lidman O, Piehl F, Hokfelt T, Karre K, et al. A role for MHC class I molecules in synaptic plasticity and regeneration of neurons after axotomy. Proc Natl Acad Sci U S A. 2004;101(51):17843-8.

38. Krukowski K, Eijkelkamp N, Laumet G, Hack CE, Li Y, Dougherty PM, et al. CD8+ T Cells and endogenous IL-10 are required for resolution of chemotherapy-induced neuropathic pain. J Neurosci. 2016;36(43):11074-83.

39. Chen $H$, Lin $W$, Zhang $Y$, Lin $L$, Chen J, Zeng $Y$, et al. IL-10 Promotes neurite outgrowth and synapse formation in cultured cortical neurons after the oxygen-glucose deprivation via JAK1/STAT3 pathway. Sci Rep. 2016;6:30459.

40. Fouda AY, Kozak A, Alhusban A, Switzer JA, Fagan SC. Antiinflammatory IL-10 is upregulated in both hemispheres after experimental ischemic stroke: hypertension blunts the response. Exp Transl Stroke Med. 2013;5(1):12

41. Zhou Z, Peng $X$, Insolera R, Fink DJ, Mata M. IL-10 promotes neuronal survival following spinal cord injury. Exp Neurol. 2009;220(1):183-90.

42. Zdanov A. Structural analysis of cytokines comprising the IL-10 family. Cytokine Growth Factor Rev. 2010;21(5):325-30.

43. Schandene L, Alonso-Vega C, Willems F, Gerard C, Delvaux A, Velu T, et al. B7/CD28-dependent IL-5 production by human resting $T$ cells is inhibited by IL-10. J Immunol. 1994;152(9):4368-74.

44. Akdis CA, Joss A, Akdis M, Faith A, Blaser K. A molecular basis for T cell suppression by IL-10: CD28-associated IL-10 receptor inhibits CD28 tyrosine phosphorylation and phosphatidylinositol 3-kinase binding. FASEB J. 2000; 14(12):1666-8 
45. Joss A, Akdis M, Faith A, Blaser K, Akdis CA. IL-10 directly acts on T cells by specifically altering the CD28 co-stimulation pathway. Eur J Immunol. 2000; 30(6):1683-90.

46. Taylor A, Verhagen J, Blaser K, Akdis M, Akdis CA. Mechanisms of immune suppression by interleukin-10 and transforming growth factor-beta: the role of T regulatory cells. Immunology. 2006;117(4):433-42.

47. Janeway CA Jr, Bottomly K. Signals and signs for lymphocyte responses. Cell. 1994;76(2):275-85

48. Ma SF, Chen YJ, Zhang JX, Shen L, Wang R, Zhou JS, et al. Adoptive transfer of M2 macrophages promotes locomotor recovery in adult rats after spinal cord injury. Brain Behav Immun. 2015;45:157-70.

49. Zhang XM, Lund H, Mia S, Parsa R, Harris RA. Adoptive transfer of cytokineinduced immunomodulatory adult microglia attenuates experimental autoimmune encephalomyelitis in DBA/1 mice. Glia. 2014;62(5):804-17.

50. Steinbrink K, Wolfl M, Jonuleit $H$, Knop J, Enk AH. Induction of tolerance by IL-10-treated dendritic cells. J Immunol. 1997;159(10):4772-80.

51. Tierney JB, Kharkrang M, La Flamme AC. Type II-activated macrophages suppress the development of experimental autoimmune encephalomyelitis. Immunol Cell Biol. 2009;87(3):235-40.

52. Hayes GM, Woodroofe MN, Cuzner ML. Microglia are the major cell type expressing MHC class II in human white matter. J Neurol Sci. 1987;80(1):25-37.

53. De Simone R, Giampaolo A, Giometto B, Gallo P, Levi G, Peschle C, et al. The costimulatory molecule B7 is expressed on human microglia in culture and in multiple sclerosis acute lesions. J Neuropathol Exp Neurol. 1995;54(2):175-87.

54. Ponomarev ED, Shriver LP, Dittel BN. CD40 expression by microglial cells is required for their completion of a two-step activation process during central nervous system autoimmune inflammation. J Immunol. 2006;176(3): 1402-10.

55. Tooyama I, Kimura H, Akiyama H, McGeer PL. Reactive microglia express class I and class II major histocompatibility complex antigens in Alzheimer's disease. Brain Res. 1990;523(2):273-80.

56. Graeber MB, Streit WJ, Kreutzberg GW. Axotomy of the rat facial nerve leads to increased CR3 complement receptor expression by activated microglial cells. J Neurosci Res. 1988;21(1):18-24.

57. Berg A, Zelano J, Thams S, Cullheim S. The extent of synaptic stripping of motoneurons after axotomy is not correlated to activation of surrounding glia or downregulation of postsynaptic adhesion molecules. PLoS One. 2013;8(3):e59647.

58. Mattsson P, Morgan BP, Svensson M. Complement activation and CD59 expression in the motor facial nucleus following intracranial transection of the facial nerve in the adult rat. J Neuroimmunol. 1998;91(1-2):180-9.

59. Hong S, Beja-Glasser VF, Nfonoyim BM, Frouin A, Li S, Ramakrishnan S, et al. Complement and microglia mediate early synapse loss in Alzheimer mouse models. Science. 2016;352(6286):712-6.

60. Heurich B, El Idrissi NB, Donev RM, Petri S, Claus P, Neal J, et al. Complement upregulation and activation on motor neurons and neuromuscular junction in the SOD1 G93A mouse model of familial amyotrophic lateral sclerosis. J Neuroimmunol. 2011;235(1-2):104-9.

61. Sta M, Sylva-Steenland RM, Casula M, de Jong JM, Troost D, Aronica E, et al. Innate and adaptive immunity in amyotrophic lateral sclerosis: evidence of complement activation. Neurobiol Dis. 2011;42(3):211-20.

62. Chiu IM, Phatnani H, Kuligowski M, Tapia JC, Carrasco MA, Zhang M, et al. Activation of innate and humoral immunity in the peripheral nervous system of ALS transgenic mice. Proc Natl Acad Sci U S A. 2009;106(49):20960-5.

63. Shen Y, Li R, McGeer EG, McGeer PL. Neuronal expression of mRNAs for complement proteins of the classical pathway in Alzheimer brain. Brain Res. 1997;769(2):391-5

64. Kawamata T, Akiyama H, Yamada T, McGeer PL. Immunologic reactions in amyotrophic lateral sclerosis brain and spinal cord tissue. Am J Pathol. 1992; 140(3):691-707.

65. Forsyth JK, Lewis DA. Mapping the consequences of impaired synaptic plasticity in schizophrenia through development: an integrative model for diverse clinical features. Trends Cogn Sci. 2017;21(10):760-78.

66. Fluiter K, Opperhuizen AL, Morgan BP, Baas F, Ramaglia V. Inhibition of the membrane attack complex of the complement system reduces secondary neuroaxonal loss and promotes neurologic recovery after traumatic brain injury in mice. J Immunol. 2014;192(5):2339-48.

67. Lopez-Redondo F, Nakajima K, Honda S, Kohsaka S. Glutamate transporter GLT-1 is highly expressed in activated microglia following facial nerve axotomy. Brain Res Mol Brain Res. 2000;76(2):429-35.
68. Kamanaka M, Huber S, Zenewicz LA, Gagliani N, Rathinam C, O'Connor W Jr, et al. Memory/effector (CD45RB(lo)) CD4 T cells are controlled directly by IL-10 and cause IL-22-dependent intestinal pathology. J Exp Med. 2011;208(5):1027-40.

69. Shouval DS, Konnikova L, Griffith AE, Wall SM, Biswas A, Werner $L$, et al. Enhanced TH17 responses in patients with IL10 receptor deficiency and infantile-onset IBD. Inflamm Bowel Dis. 2017;23(11):1950-61.

70. Martinez-Forero I, Garcia-Munoz R, Martinez-Pasamar S, Inoges S, Lopez-Diaz de Cerio A, Palacios R, et al. IL-10 suppressor activity and ex vivo Tr1 cell function are impaired in multiple sclerosis. Eur J Immunol. 2008;38(2):576-86.

71. Cui HD, Qi ZM, Yang LL, Qi L, Zhang N, Zhang XL, et al. Interleukin-10 receptor expression and signalling were down-regulated in CD4(+) T cells of lupus nephritis patients. Clin Exp Immunol. 2011;165(2):163-71.

72. Jones TB, Ankeny DP, Guan Z, McGaughy V, Fisher LC, Basso DM, et al. Passive or active immunization with myelin basic protein impairs neurological function and exacerbates neuropathology after spinal cord injury in rats. J Neurosci. 2004;24(15):3752-61.

73. Ankeny DP, Popovich PG. Central nervous system and non-central nervous system antigen vaccines exacerbate neuropathology caused by nerve injury. Eur J Neurosci. 2007;25(7):2053-64.

74. Ford AL, Foulcher E, Lemckert FA, Sedgwick JD. Microglia induce CD4 T lymphocyte final effector function and death. J Exp Med. 1996;184(5):1737-45.

75. DeBoy CA, Byram SC, Serpe CJ, Wisuri D, Sanders VM, Jones KJ. CD4 + CD25+ regulatory $T$ cells and CD1-restricted NKT cells do not mediate facial motoneuron survival after axotomy. J Neuroimmunol. 2006;176(1-2):34-8.

76. Zhou L, Chong MM, Littman DR. Plasticity of CD4+ T cell lineage differentiation. Immunity. 2009;30(5):646-55.

\section{Publisher's Note}

Springer Nature remains neutral with regard to jurisdictional claims in published maps and institutional affiliations.

Ready to submit your research? Choose BMC and benefit from:

- fast, convenient online submission

- thorough peer review by experienced researchers in your field

- rapid publication on acceptance

- support for research data, including large and complex data types

- gold Open Access which fosters wider collaboration and increased citations

- maximum visibility for your research: over $100 \mathrm{M}$ website views per year

At $\mathrm{BMC}$, research is always in progress.

Learn more biomedcentral.com/submission 